\title{
Analysis of a southern sub-polar short-term ozone variation event using a millimetre-wave radiometer
}

\author{
Pablo Facundo Orte ${ }^{1}$, Elian Wolfram ${ }^{1,2,3}$, Jacobo Salvador ${ }^{1,2}$, Akira Mizuno ${ }^{4}$, Nelson Bègue ${ }^{5}$, Hassan Bencherif ${ }^{5,8}$, \\ Juan Lucas Bali ${ }^{1,2}$, Raúl D'Elia ${ }^{1,2}$, Andrea Pazmiño ${ }^{6}$, Sophie Godin-Beekmann ${ }^{6}$, Hirofumi Ohyama ${ }^{7}$, and \\ Jonathan Quiroga ${ }^{1}$ \\ ${ }^{1}$ Centro de Investigaciones en Láseres y Aplicaciones, UNIDEF (CITEDEF-CONICET), UMI-IFAECI-CNRS-3351, \\ Villa Martelli, Buenos Aires, Argentina \\ ${ }^{2}$ Facultad Regional Buenos Aires, Universidad Tecnológica Nacional, Buenos Aires, Argentina \\ ${ }^{3}$ Consejo Nacional de Investigaciones Científicas y Técnicas (CONICET), Buenos Aires, Argentina \\ ${ }^{4}$ Institute for Space-Earth Environmental Research, Nagoya University, Furo-cho, Chikusa-ku, \\ Nagoya 464-8601, Japan \\ ${ }^{5}$ Laboratoire de l'Atmosphère et des Cyclones, UMR 8105 CNRS/Universite/Météo-France, \\ Université de La Réunion, B.P 7151, 97715, Saint-Denis, La Réunion, France \\ ${ }^{6}$ Laboratoire Atmosphère, Milieux, Observations Spatiales (LATMOS), Institut Pierre Simon Laplace, Université Pierre et, \\ Marie Curie, Université Versailles St-Quentin-en-Yvelines, Centre National de la Recherche Scientifique, Paris, France \\ ${ }^{7}$ National Institute for Environmental Studies (NIES), Tsukuba, Japan \\ ${ }^{8}$ University of KwaZulu-Natal, School of Chemistry and Physics, Westville, Durban, South Africa
}

Correspondence: Pablo Facundo Orte (porte@ citedef.gob.ar)

Received: 30 January 2019 - Discussion started: 18 February 2019

Revised: 26 June 2019 - Accepted: 1 July 2019 - Published: 24 July 2019

\begin{abstract}
Subpolar regions in the Southern Hemisphere are influenced by the Antarctic polar vortex during austral spring, which induces high and short-term ozone variability at different altitudes, mainly into the stratosphere. This variation may affect considerably the total ozone column changing the harmful UV radiation that reaches the surface.

With the aim of studying ozone with a high time resolution at different altitudes in subpolar regions, a millimetre-wave radiometer (MWR) was installed at the Observatorio Atmosférico de la Patagonia Austral (OAPA), Río Gallegos, Argentina $\left(51.6^{\circ} \mathrm{S}, 69.3^{\circ} \mathrm{W}\right)$, in 2011 . This instrument provides ozone profiles with a time resolution of $\sim 1 \mathrm{~h}$, which enables studies of short-term ozone mixing ratio variability from 25 to $\sim 70 \mathrm{~km}$ in altitude. This work presents the MWR ozone observations between October 2014 and 2015, focusing on an atypical event of the polar vortex and Antarctic ozone hole influence over Río Gallegos detected from the MWR measurements at 27 and $37 \mathrm{~km}$ during November of 2014. During the event, the MWR observations at both altitudes show a decrease in ozone followed by a local peak of ozone amount
\end{abstract}

of the order of hours. This local recovery is observed thanks to the high time resolution of the MWR mentioned. The advected potential vorticity (APV) calculated from the MIMOSA high-resolution advection model (Modélisation Isentrope du transport Méso-échelle de l'Ozone Stratosphérique par Advection) was also analysed at two isentropic levels (levels of constant potential temperature) of 675 and $950 \mathrm{~K}$ ( $\sim 27$ and $\sim 37 \mathrm{~km}$ of altitude, respectively) to understand and explain the dynamics at both altitudes and correlate the ozone rapid recovery with the passage of a tongue with low PV values over Río Gallegos. In addition, the MWR dataset was compared for the first time with measurements obtained from the Microwave Limb Sounder (MLS) at individual altitude levels (27, 37 and $65 \mathrm{~km}$ ) and with the differential absorption lidar (DIAL) installed in the OAPA to analyse the correspondence between the MWR and independent instruments. The MWR-MLS comparison presents a reasonable correlation with mean bias errors of $+5 \%,-11 \%$ and $-7 \%$ at 27,37 and $65 \mathrm{~km}$, respectively. The MWR-DIAL compar- 
ison at $27 \mathrm{~km}$ also presents good agreement, with a mean bias error of $-1 \%$.

\section{Introduction}

Ozone is an atmospheric trace compound which reaches its absolute maximum concentration in the stratosphere between 15 and $35 \mathrm{~km}$, where it forms the "ozone layer" (London et al., 1985). It acts as an absorber of harmful solar UVB radiation, protecting life on Earth (Salby, 1996; Dobson, 1956). Without atmospheric ozone, life would not be possible as we know it today. Although most production takes place in the mesospheric-stratospheric equatorial region due to the higher level of solar radiation, the maximum ozone concentration is observed over the polar region (Salby, 1996). This zonal distribution is explained by the Brewer-Dobson circulation (Brewer, 1949; Dobson, 1956), which transports ozone-rich air masses from the Equator to the pole and into the stratosphere.

Nevertheless, since the 1970s the ozone layer has suffered a drastic reduction over the Antarctic region inside the polar vortex during the austral spring seasons, known as the "Antarctic ozone hole" (AOH) (Chubachi, 1984; Farman et al., 1985). This ozone destruction is the consequence of human emission of components containing chlorine and bromine into the atmosphere, called ozone-depleting substances (ODS) (WMO, 2011a). The most direct impact of ozone reduction is the increase in harmful solar UVB radiation over the surface in the polar and subpolar regions (Casiccia et al., 2008; Wolfram et al., 2012).

With the aim of reducing ODS and mitigating ozone depletion, the Montreal Protocol was signed in 1987 banning the use of ODS, and a decrease in these substances in the atmosphere was observed (WMO, 2014). However, the lifetime of these compounds in the atmosphere is very long (e.g. 100 years for some of them) (Rigby et al., 2013; WMO, 2014), and they will remain for decades in the atmosphere, destroying ozone mainly over the Antarctic polar region.

In spite of the fact that massive ozone depletion is produced over the South Pole, ozone reductions at different height levels were also observed in non-polar regions between the 1980s and 1990s (WMO, 2014). Kirchhoff et al. (1997a, b) reported total ozone column (TOC) ranging from 145 to $250 \mathrm{DU}$ in Punta Arenas (53.0' S, 70.9' W), during low-ozone events during September-December of 19921995 , for which the climatological average is $330-334 \mathrm{DU}$ (maximum reduction of $\sim 56 \%$ ). A more recent study reported a reduction of $40 \%-45 \%$ in TOC over Río Gallegos in October 2008 and November 2009 (Kuttippurath et al., 2010). ECC (electrochemical cell) ozone-sonde profile measurements reflect reductions of around $30 \%$ to $50 \%$ between 15 and $32 \mathrm{~km}$ of altitude in the ozone hole condition (inner) with respect to normal conditions (outside the ozone hole) in Punta Arenas (Kirchhoff et al., 1997a). A similar reduction was observed from a differential absorption lidar at Río Gallegos (Wolfram et al., 2006).

Together with the banning in the use of ODS set by the 1987 Montreal Protocol, the general expectation was that the TOC would recover as the amount of ODS decreased in all regions. Recent studies showed a recovery of the stratospheric ozone column during September (statistically significant) and October (statistically insignificant) for the southern polar region (Solomon et al., 2016; Weber et al., 2018; Pazmiño et al., 2018). Ground- and space-based observations and models have shown an increase in the total ozone since 2000. Nevertheless, this increase is not significant for the period 2000-2013 (WMO, 2014). Ball et al. (2018) extended this period from 1998 to 2016 and concluded that there are non-significant changes in the total amount of ozone from merged ozone datasets.

Recent partial column ozone analysis from satellite ozone composites indicates a decadal increase in the upper stratosphere that is statistically significant (WMO, 2014; Harris et al., 2015; Steinbrecht et al., 2017; Ball et al., 2017, 2018; Frith et al., 2017), attributed in part to the decline of the ODS. On the other hand, an unexpected decrease in the partial column ozone in the lower stratosphere has been suggested, although with a low level of confidence (Nair et al., 2015; Vigouroux et al., 2015; Ball et al., 2018). A globalscale study (between $60^{\circ} \mathrm{N}$ and $60^{\circ} \mathrm{S}$ ) confirmed a significant decrease in partial column ozone in the lower stratosphere at tropical latitudes with a high level of significance, accounting for a continued and uninterrupted decline of the order of 2.2 DU between 1998 and 2016 (Ball et al., 2018).

During the austral spring time, the Antarctic polar vortex changes its size and shape, and it can reach subpolar regions due mainly to tropospheric-stratospheric dynamical processes. Hence, the Antarctic polar vortex can overpass the continental South American region in subpolar latitudes, and this situation may provoke decreases in the TOC content to unusual levels due to the passage of masses with low ozone amounts, as a consequence of the AOH influence (Pazmiño et al., 2005; Wolfram et al., 2008). The passage of the AOH is identified using the TOC threshold of $220 \mathrm{DU}$, while other considerable reductions in ozone above $220 \mathrm{DU}$ in links to the polar vortex are mentioned as the "ozone hole influence". A particular case of unusual persistence of the AOH influence over southern Argentina was observed during November 2009 with satellite and ground-based instruments, which led to an increase in the risk of UVB radiation on the surface (Wolfram et al., 2012). This phenomenon was first observed by Kirchhoff et al. (1996) and reported by Pinheiro et al. (2011) in South America. Recently, based on satellite and ground-based observations in Uruguay and southern Brazil, Bresciani et al. (2018) showed a decrease in ozone over these sites during October 2016 due to the influence of the $\mathrm{AOH}$ reaching mid-latitudes. 
The air-mass transport in the stratosphere has been extensively analysed using the advected potential vorticity (APV), which is considered a suitable dynamical tracer in the stratosphere. The transport of polar air masses may take the form of "filaments" or a "tongue". These terms have been used to explain the transport of air from the edge of the polar vortex into mid-latitudes by Waugh (1993), analysing potential vorticity maps, and previously by Randel et al. (1993) to explain the intrusion of tropical air into mid-latitudes. When the intrusion of air from the polar vortex reaches mid-latitudes and produces ozone decreases, it induces anomalies on the surface UV radiation. Bittencourt et al. (2018) also linked the occurrence of this event over South America to later changes in the tropospheric and stratospheric dynamic behaviour. Thus, this parameter can be used to study the dynamics of the Antarctic polar vortex and as a tracer of poorozone air masses that are released from the $\mathrm{AOH}$ (Bittencourt et al., 2018; Kirchhoff et al., 1996; Pinheiro et al., 2011; Wolfram et al., 2012; Hauchecorne et al., 2002; Marchand et al., 2005; Bencherif et al., 2007).

In this paper we analyse an unusual event of rapid decrease in and recovery of a volume mixing ratio over Río Gallegos, Argentina, during November 2014 due to the release of a tongue of a poor-ozone air mass. This analysis was achieved by means of ground- and space-based instruments, focusing on the millimetre-wave radiometer (MWR) ozone measurements. The high temporal resolutions $(1 \mathrm{~h})$ of the MWR observations are analysed at different altitudes (27 and $37 \mathrm{~km}$ ) with the aim of determining the short-term variability of the ozone mixing ratio and the moment when the polar vortex and its edge (as tongue or filamentary structure) with poorozone air masses pass over Río Gallegos and leave it at those altitudes, resulting in a local peak of the ozone mixing ratio for a very short period of time in November 2014. TOC measurements are also analysed by the SAOZ ground-based instrument installed in the Observatorio Atmosférico de la Patagonia Austral (OAPA) and by the Ozone Monitoring Instrument (OMI) satellite. Finally, the APV field from the MIMOSA model was used to analyse the air-mass transport during the event. In addition, the MWR ozone mixing ratio retrieved in Río Gallegos is compared for the first time with ground-based measurements from the ozone DIAL/NDACC instrument and satellite measurements from the MLS onboard the AURA/NASA.

This paper is organized as follows: Sect. 2 describes the ground- and satellite-based ozone instrument and the MIMOSA model used to calculate APV to determine the origin of air masses over Río Gallegos. In addition, this section describes the instrumental datasets used in this research and the methodology to analyse the correspondence of the MWR with respect to the ground-based DIAL instrument and the MLS ozone profile at the analysed altitudes. The results of the comparisons are detailed in Sect. 3. In Sect. 4, the atypical ozone event that occurred during November 2014 was analysed at 27 and $37 \mathrm{~km}$, with a resolution of $1 \mathrm{~h}$ determin- ing the rapid variation of the ozone mixing ratio over Río Gallegos. Finally, the solar Ultraviolet Index (UVI) at the surface is also analysed during the event.

\section{Materials and methodology}

\subsection{Observations}

Ground-based instruments used here are operated at the OAPA, Río Gallegos, Argentina (51.5 $\left.\mathrm{S}, 69.3^{\circ} \mathrm{W}\right)$, belonging to CEILAP (hereafter the OAPA). The geographical location of the OAPA makes it a suitable site to study the subpolar stratospheric ozone due to its closeness to Antarctica. Since 2005, a differential absorption lidar (DIAL) has been operated at the OAPA with the aim of retrieving stratospheric ozone profiles (Wolfram, 2006; Salvador, 2011), which were joined to the Network for the Detection Composition Change (NDACC) in 2008 (http://www.ndaccdemo.org/, last access: November 2016). In addition, a ground-based SAOZ spectrometer instrument (Pommereau and Goutail, 1988) to retrieve TOC was installed in the OAPA by 2008 , which belongs to LATMOS/CNRS. To contribute to ozone monitoring, the Solar Terrestrial Environment Laboratory, Nagoya University, Japan, installed the MWR in the OAPA in 2011, which incremented the temporal resolution and increased the altitude range of the ozone profiles (Orte et al., 2011; Orte, 2017). Due to the relationship between ozone amount and the solar UVB radiation at surface, this parameter is also measured in the OAPA with a ground-based solar radiometer, YES UVB-1 (Yankee Environmental System, Inc.).

It is important to highlight that the MWR installed in the OAPA is one of few ground-based radiometers able to observe ozone in the Southern Hemisphere and the unique installed MWR in the subpolar region. In this hemisphere, other ozone radiometers can be found in the Antarctic region in Syowa station and in Halley station (moved from the Troll station in 2013) (Isono et al., 2014; Daae et al., 2014), and at mid-latitudes, in Lauder, New Zealand (McDermid et al., 1998). The MWR installed in the OAPA allows one to improve the understanding of the stratospheric and low-mesospheric dynamic using the ozone mixing ratio as a tracer and improving the validation of dynamical models at these latitudes.

Satellite instruments used here are another useful dataset to measure ozone on a global scale and analyse the ozone layer behaviour. In this work, OMI satellite and MLS datasets are used to inter-compare with the ground-based MWR instrument.

\subsubsection{Millimetre-wave radiometer}

The MWR is a fully automated instrument which belongs to Nagoya University. It retrieves ozone profiles ranging from $\sim 25$ and $\sim 70 \mathrm{~km}$ vertical range with a temporal resolution of the order of $1 \mathrm{~h}$, allowing for the study of the short-term 
variability of this gas. The vertical resolution ranges from $\sim 10$ to $\sim 14 \mathrm{~km}$ up to $48 \mathrm{~km}$ in height, increasing to $16 \mathrm{~km}$ above the middle mesosphere.

The MWR system is based on a superheterodyne receiver employing a superconductor-insulator-superconductor (SIS) mixer cooled at $4 \mathrm{~K}$ used to convert the ozone signal at $\sim$ $110.83 \mathrm{GHz}$ down to the intermediate frequency.

The MWR is basically composed of a rotating mirror, a quasi-optical mirror system, a superheterodyne receiver and a spectrometer. Figure 1 shows a scheme of the system installed at the OAPA. The rotating mirror looks toward four directions to acquire the signal from two different zenith angles, $S_{\text {low }}$ and $S_{\text {high }}$, and from two known reference blackbody loads to calibrate the signal from voltage to brightness temperature. $S_{\text {high }}$ comes from the zenith and it is re-directed to the rotating mirror by a fixed plane mirror, while $\mathrm{S}_{\text {low }}$ comes from a zenith angle of between 12 and $38^{\circ}$. A dielectric plate is installed through the $S_{\text {high }}$ path to increment the continuum levels of the spectrum, and then a servosystem is in charge to equalize both signals. A full description of the measurement technique can be found in Mizuno et al. (2002) and Parrish et al. (1988).

The calibration loads consist of two blackbodies at different temperatures, hot and cold. The hot blackbody load is achieved using a radio absorber at room temperature $(\sim$ $300 \mathrm{~K}$ ), while the cold load is achieved by soaking a similar absorber in liquid nitrogen $(77 \mathrm{~K}$ ) contained in a Dewar glass (vacuum bottle made of glass that is used especially for storing liquefied gases). The liquid nitrogen is obtained automatically using a compressor refrigerator of environmental nitrogen. To reduce the standing waves (baseline), a pass length modulator (PLM) is inserted into the signal path which consists of a pair of roof-top mirrors (Mizuno et al., 2002).

The receiver is basically composed of a local oscillator (LO) and the SIS mixer (Ogawa et al., 1990). This system converts the input signal emitted by the atmospheric ozone molecules in their rotational transitions $(\sim 110836 \mathrm{GHz})$ into the lower intermediate frequency (IF $\sim 6 \mathrm{GHz}$ ). The mixer operates in single side band (SSB) using a wave guide to filter the image band (Asayama et al., 2015), and it is cooled at $4 \mathrm{~K}$ to reach the superconductive state. This operational temperature improves the signal-to-noise ratio to obtain a high temporal resolution $(\sim 1 \mathrm{~h})$. The temperature is achieved using a liquid helium closed-loop cryogenic refrigerator (DAIKIN CG308, three-stage GM-JT).

Then, the IF is amplified by a HEMT (high-electron mobility transistor) cooled to $15 \mathrm{~K}$. The subsequent components (filters, amplifiers and attenuators) are designed to process the IF signal and fit it to the spectrometer requirements. The spectrometer is a digital FFT (DFS) Acquaris AC240 with 16384 channels and a bandwidth and spectral resolution of $1 \mathrm{GHz}$ and $68 \mathrm{KHz}$, respectively. Finally, the observed spectrum in brightness temperature is obtained, assuming a linear behaviour among the sky signal $\left(\mathrm{S}_{\mathrm{low}}\right.$ and $\left.\mathrm{S}_{\mathrm{high}}\right)$, the hot blackbody signal $\left(\mathrm{S}_{\mathrm{hot}}\right)$ and the cold blackbody signal $\left(\mathrm{S}_{\mathrm{cold}}\right)$ measurements by the following expression:

$T_{\text {oi }}=\frac{T_{\text {hot }}-T_{\text {cold }}}{S_{\text {hot }}-S_{\text {cold }}}\left(S_{\text {low }}-S_{\text {high }}\right)$.

The method adopted here for the ozone profile retrieval is the optimal estimation method (OEM) described by Rodgers (2000).

The forward model comparable to the measurement is calculated by means of the Atmospheric Radiative Transfer Simulator (ARTS). Detailed documentation can be found in http://www.radiativetransfer.org/docs/ (last access: August 2013). The Qpack2 (Eriksson, 2005) is a package of Matlab routines used to set up the ARTS model, and it has included the OEM calculation for general cases.

The input pressure and temperature for the forward model were obtained by combining the NCEP reanalysis data up to $\sim 30 \mathrm{~km}$ with the CIRA climatology above, interpolated for the MWR measurement time and site location. As an input a priori ozone profile, we used monthly zonal daytime and night-time MLS $\mathrm{O}_{3}$ climatology between $\sim 15$ and $75 \mathrm{~km}$, completed with zonal climatology below and above (McPeters et al., 2012). A full description of the inversion can be found in Orte (2017).

\subsubsection{DIAL (differential absorption lidar)}

The ozone DIAL used here was developed by the Centro de Investigación en Láseres y Aplicaciones (CEILAP) in collaboration with the Laboratoire Atmosphères, Milieux, Observations Spatiales (LATMOS; http://www.latmos.ipsl.fr, last access: July 2019) between 2003 and 2005 (Wolfram, 2006; Salvador, 2011). The ozone profile retrieval algorithms were provided by the Observatory of Haute-Provence (OHP) (Godin, 1987; Godin-Beekmann et al., 2003; Pazmiño, 2003), which were adapted for the DIAL system installed in the OAPA, Río Gallegos (51.6 $\left.\mathrm{S}, 69.3^{\circ} \mathrm{W}\right)$, by mid-2005. Since the installation, instrumental and algorithm improvements have been carried out (Salvador, 2011).

DIAL is an active and self-calibrated remote sensing technique similar to radar but using pulses of laser radiation in the ultraviolet range. This instrument requires the emission of two lasers directed to the atmosphere at two different wavelengths: $308 \mathrm{~nm}\left(\lambda_{\text {on }}\right)$ and $355 \mathrm{~nm}\left(\lambda_{\text {off }}\right)$. A ClXe excimer laser is responsible for emitting the laser beam at the wavelength $\lambda_{\text {on }}$, which is absorbed by the atmospheric ozone molecules, while $\lambda_{\text {off }}$ is the reference wavelength produced by the third harmonic of an Nd-YAG laser. The interaction of this laser's radiation with the atmospheric molecules causes scattering following a known spatial distribution, and the photons backscattered in the direction of the instrument are collected by four Newtonian telescopes with a diameter of $50 \mathrm{~cm}$ each, which have an aluminized reflective parabolic surface. These photons are reflected and focused on four optical fibres, each located in the focus of each parabolic mirror. The photons are conducted to a mechanical chopper po- 


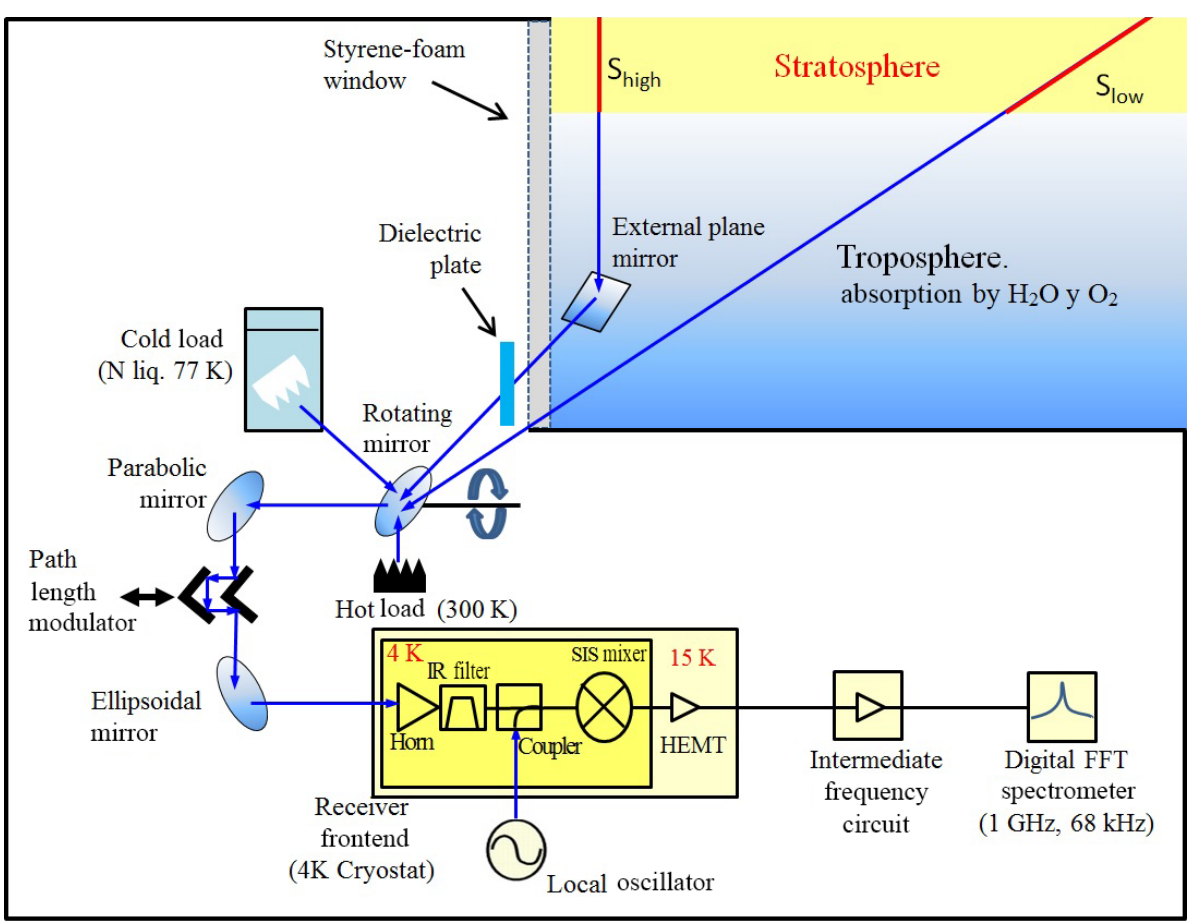

Figure 1. Block diagram of the MWR at the OAPA, Río Gallegos $\left(51.6^{\circ} \mathrm{S}, 69.3^{\circ} \mathrm{W}\right)$.

sitioned before the spectrometer to filter the backscattered lidar signal from the bottom of the atmosphere. Finally, a spectrometer is used to separate the backscattered signal at different wavelengths. These signals are then integrated in time $(\sim 3 \mathrm{~h})$ and processed by the retrieval algorithm to obtain ozone profiles. The DIAL instrument covers an altitude range from $\sim 15$ to $\sim 40 \mathrm{~km}$ under optimal operating conditions with a vertical resolution between 0.5 and $5 \mathrm{~km}$, depending on the altitude, and it can only operate during clearsky nights. The typical uncertainty associated with this instrument varies between $3 \%$ and $15 \%$ from 14 to $35 \mathrm{~km}$ (Wolfram et al., 2012).

\subsubsection{AURA satellites: MLS and OMI}

The MLS (Microwave Limb Sounder) was launched on 15 July 2004 onboard the AURA satellite and began to operate on 13 August 2004. Since then, this instrument has been able to observe the thermal emission of the atmosphere in the range of submillimetre and millimetre waves. The Earth's limb viewing allows the MLS to achieve a higher altitude resolution ( $\sim 3 \mathrm{~km}$ in the stratosphere and $\sim 5 \mathrm{~km}$ in the mesosphere) compared to MWR. A full description of the MLS instrument can be found in Waters et al. (2006). MLS ozone profile data versions 3.3 and 3.4 (Livesey et al., 2013) were used (http://mls.jpl.nasa.gov, last access: January 2016).

The OMI, onboard the AURA satellite, started TOC measurements in 2004, with the aim of continuing the TOMS satellite record. It was launched in July 2004 in the frame- work of the Earth Observing System (EOS) project. In addition to ozone, the OMI retrieves atmospheric components such as total contents of $\mathrm{NO}_{2}, \mathrm{SO}_{2}$, and aerosols. This instrument measures the reflected and backscattered solar radiation by a UV-VIS spectrometer with a spectral resolution ranging from $\sim 0.45$ to $\sim 0.63 \mathrm{~nm}$ in nadir view and provides nearly global coverage in 1 day with a spatial resolution ranging from 13 to $24 \mathrm{~km}$ (Levelt et al., 2006). In this work, we used the TOC overpass product from the OMI (OMDOAO3). The dataset can be downloaded from https://avdc.gsfc.nasa.gov/ index.php?site=2045907950 (last access: July 2019).

\subsubsection{SAOZ (Systeme d'Analyse par Observation Zenithale)}

The ground-based SAOZ UV-VIS $(300-650 \mathrm{~nm})$ spectrometer instrument (Pommereau and Goutail, 1988) used in this work was installed in the OAPA observatory on 11 March 2008, and it belongs to LATMOS/CNRS. SAOZ measures the sunlight scattered from the zenith sky. The differential optical absorption spectroscopy (DOAS) method is applied to retrieve total ozone and nitrous dioxide columns twice a day at high solar zenith angles between 86 and $91^{\circ}$ at sunrise and sunset. TOC measurements are performed in the Chappuis visible band $(450-550 \mathrm{~nm})$ where ozone cross sections are not very dependent on temperature. The spectral resolution of the SAOZ installed at Río Gallegos is $0.9 \mathrm{~nm}$. SAOZ retrieval follows UV-VIS NDACC Working Group recommendations: spectral window analysis, ab- 
sorption cross sections and daily air mass factor to convert measured slant column densities (SCDs) into vertical column densities (VCDs). In the case of ozone, look-up tables (LuTs) of air mass factors are used (Hendrick et al., 2011). The LuTs were obtained from the UVSPEC/DISORT radiative transfer model using the TOMS V8 ozone and temperature profiles' climatology. This SAOZ joined the NDACC network in 2009 and the dataset can be downloaded from the SAOZ webpage (http://saoz.obs.uvsq.fr/SAOZ-RT.html, last access: March 2018) and NDACC webpage (http://www. ndaccdemo.org/, last access: March 2018).

\subsubsection{Solar radiometer YES UVB-1}

The YES UVB-1 ground-based radiometer (Yankee Environmental System, Inc.) installed in the OAPA is used to measure the UVB irradiance at the surface, and the UVI is retrieved. It is connected to a data logger, which is configured to acquire one measurement per minute. Due to the UVI being strongly affected by the ozone amount in the atmosphere, the time evolution of the daily maximum UVI is analysed during the period of the case study. We decided to present the daily maximum UVI instead of the UVI at solar noon due to the fact that most of the analysed days during the low-ozone event were partially cloudy and the maximum UVI was observed near the solar noon. Thus, the daily maximum UVI is more representative in terms of the low-ozone amount impact over the UVI at the surface.

\subsection{MIMOSA model}

The Modélisation Isentrope du transport Méso-échelle de l'Ozone Stratosphérique par Advection (MIMOSA) highresolution advection model was used here to determine the origin of air masses similar to an isentropic Lagrangian trajectory model. The MIMOSA dynamical model is specifically used to describe filamentary structure through the APV on isentropic levels (Hauchecorne et al., 2002; Godin et al., 2002). The advection is driven by ECMWF meteorological analyses at a resolution of $0.5^{\circ} \times 0.5^{\circ}$. It is possible to run the model continuously and follow the evolution of PV filaments for several months. The accuracy of the model has been evaluated by Hauchecorne et al. (2002) and validated against airborne lidar ozone measurements using a correlation between PV and ozone (Heese et al., 2001; Godin et al., 2002; Jumelet et al., 2009). The ability of the MIMOSA model to determine the origin of air masses influencing a given site has been highlighted in several studies (Hauchecorne et al., 2002; Bencherif et al., 2003; Jumelet et al., 2009; Bègue et al., 2017). Moreover, the MIMOSA model is frequently used to detect the origin of air masses inducing laminae on ozone profiles (Hauchecorne et al., 2002; Godin et al., 2002; Portafaix et al., 2003). A full description of this model can be found in Hauchecorne et al. (2002).

\subsection{Methodological considerations}

Fifteen months of MWR, MLS and DIAL ozone measurements at different altitudes over the OAPA were analysed, from October 2014 to December 2015. Figure 2 shows the time series of ozone mixing ratios observed by the MWR (blue) and the MLS (red) for altitudes of 27, 37, and $65 \mathrm{~km}$. The first two levels are established in such a way that they are representative of the amount and variability of ozone within the stratosphere, in the dynamic range of the instrument. In addition, around $37 \mathrm{~km}$ the maximum of the average ozone mixing ratio occurs for Río Gallegos. The level of $65 \mathrm{~km}$ was included to observe the sensitivity of the MWR in the mesosphere within the diurnal cycle. We observe a marked difference of ozone mixing ratio between day and night measurements due to the ozone photochemistry around this altitude (Allen et al., 1984; Nagahama et al., 1999). In general, we can observe that the behaviour of the MWR and MLS measurements for all analysed altitudes is similar.

The MWR has a temporal resolution of $\sim 1 \mathrm{~h}$, while the MLS presents measurements close to the OAPA with an approximate frequency of one measurement every 2 days at 19:00 UTC approximately and two monthly measurements at 05:00 UTC approximately. This frequency is conditioned by the orbit of the AURA satellite. In order to obtain a significant number of profiles to make the comparison, the MLS observations were selected within a box of \pm 0.2 in latitude and $\pm 5^{\circ}$ in longitude from the OAPA location, considering that both instruments were observing the same air mass. Figure 3 shows the position of the MLS measurements selected for the inter-comparison (yellow crosses) and the location of the OAPA (blue dot), where the MWR is located. Numbers below crosses indicate the number of each group of MLS measurements in each location. The time differences between MWR and MLS measurement inter-comparison pairs were less than $30 \mathrm{~min}$. Given that MLS measurements are not collocated with the MWR, some differences between instruments could be due to the distance between instruments, mainly during spring when the AOH may influence and produce large difference of ozone mixing ratios in short distances.

While the MWR and the MLS operate automatically, DIAL requires manual operation in clear-sky nights. DIAL monitoring in 2014 and 2015 was intensive during spring (October, November, December) and it was possible to obtain a few measurements if we compare with the high quantity of measurements provided by the MWR and the MLS. The DIAL dataset is not shown in Fig. 2, but in Fig. 6 in the next section. For the MWR-DIAL inter-comparison pairs we take the MWR measurements in the middle of the $\sim 3 \mathrm{~h}$ integrated interval of the DIAL measurement.

The ozone measurements obtained by DIAL are in molec $\mathrm{m}^{-3}$, while the MWR and MLS measurements are in volume mixing ratio. Thus, temperature and pressure 


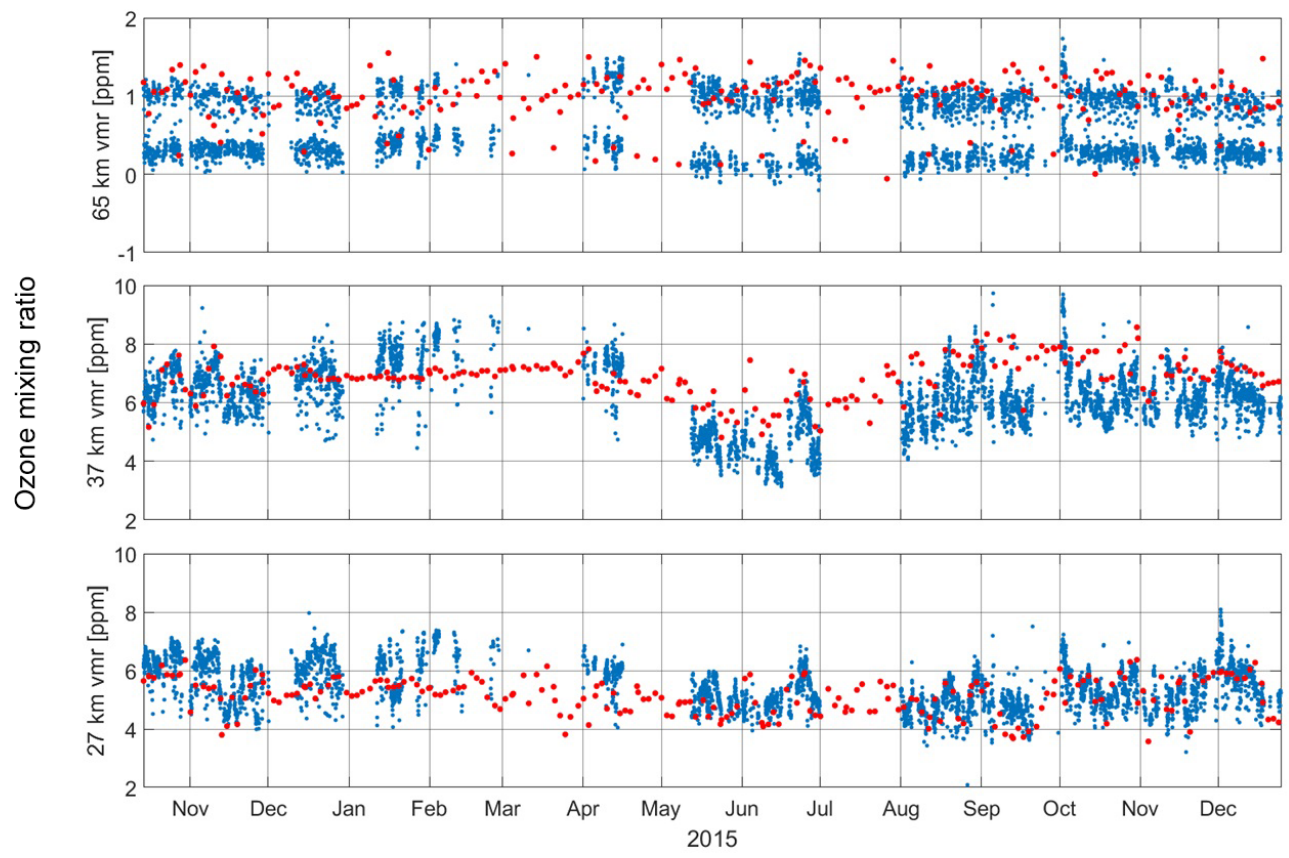

Figure 2. Time series of MLS (red dots) and MWR (blue dots) ozone mixing ratios for three altitudes: 27,37 and 65 km between October 2014 and December 2015 (the MWR was inoperative during March and July 2015 due to technical problems).

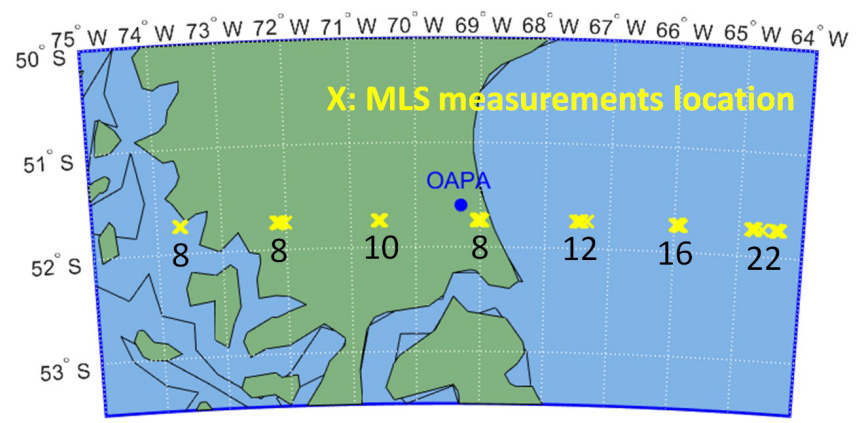

Figure 3. MWR location (blue dot, OAPA) and MLS measurement location (yellow crosses) used in the inter-comparison. The numbers below crosses indicate the quantity of MLS measurements.

from NCEP reanalysis data are then used to convert from molec $\mathrm{m}^{-3}$ to volume mixing ratio.

Due to the fact that MLS and DIAL have a better vertical resolution than the MWR, the MLS and DIAL profiles were degraded to the MWR resolution taking into account the averaging kernel functions $\mathrm{A}$, which represent the response of the retrieved ozone profile to the "true" one. The following expression was used to degrade the vertical resolution (Palm et al., 2010):

$x_{\mathrm{LR}}=x_{\mathrm{a}}+A\left(x_{\mathrm{HR}}-x_{\mathrm{a}}\right)$,

where $x_{\mathrm{HR}}$ is the MLS or DIAL ozone profile (depending on which instrument is inter-compared with the MWR) with the original vertical resolution. $x_{\mathrm{a}}$ and $A$ are the a priori ozone profile and the averaging kernel function used in the MWR inversion, and $x_{\mathrm{LR}}$ are the MLS or DIAL ozone profiles degraded to the MWR vertical resolution. Since the ozone DIAL profile is limited in altitude range with respect to the millimetre-wave radiometer, it is completed below and above the measurement with MLS climatologies interpolated to the OAPA location.

The main source of millimetre-wave opacity that impacts radiation coming from ozone molecules in the stratosphere and the mesosphere is water vapour, mainly contained in the troposphere. The opacity is retrieved by the MWR during the measurement cycle (Orte, 2017). Only measurements taken when atmospheric opacity was less than 0.29 were considered. This criterion was defined taking into account the mean value and the variability of the opacity for Río Gallegos, measured by the MWR $\left(\mu_{\tau}=0.225 ; \sigma_{\tau}=0.041\right)$ for the analysed period and studying the correlation between MLS and MWR. We noted that the correlation between MLS and MWR at different altitudes increases when opacity decreases (not presented here)

To evaluate the correspondence between instruments, the mean bias error (MBE) was calculated between the MWR and the DIAL and MLS measurements $\left(x_{\mathrm{LR}_{\mathrm{A}}}\right)$ for the considered altitudes $(27,37$ and $65 \mathrm{~km})$ :

$\mathrm{MBE}=100 \times \frac{\overline{\mathrm{MWR}_{\mathrm{A}}}-\overline{x_{\mathrm{LR}_{\mathrm{A}}}}}{\overline{x_{\mathrm{LR}_{\mathrm{A}}}}}$, 


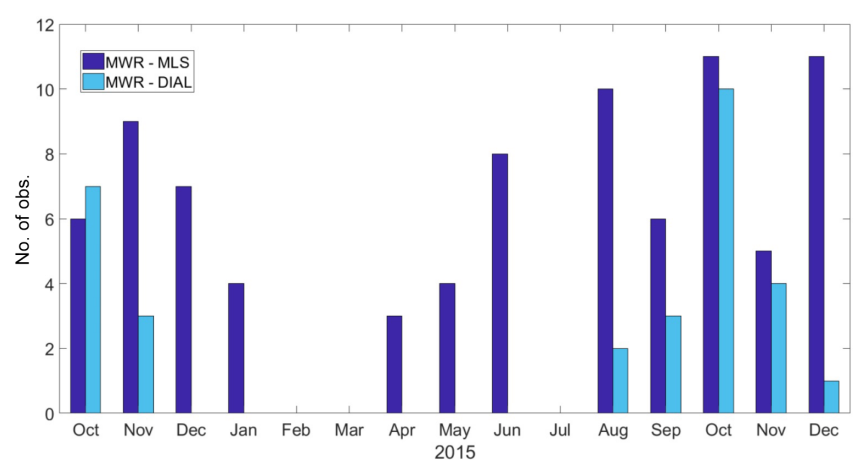

Figure 4. Number of inter-compared measurement pairs for each month. Blue bars represent the number of MWR-MLS pairs, while light blue bars are the number of MWR-DIAL pairs.

where $\overline{\mathrm{MWR}_{\mathrm{A}}}$ is the average of the MWR ozone mixing ratio at each altitude and $\overline{x_{L R_{A}}}$ is the average of the DIAL or MLS measurements at the same altitude.

Finally, a linear regression analysis between each dataset pair at each altitude was performed and the correlation coefficient $R$ was analysed.

\section{Results}

\subsection{Inter-comparison of the MWR with DIAL and MLS observations}

With the aim of analysing the correspondence of the MWR to independent instruments, inter-comparisons of the ozone mixing ratio with respect to the ground-based DIAL instrument and satellite-based MLS were carried out at 27, 37 and $65 \mathrm{~km}$.

Figure 4 shows the number of time overlap measurements inter-compared between MWR and MLS (blue bars) and MWR and DIAL (light blue bars) during the period described in Fig. 2. A total number of 84 MWR-MLS and 30 MWR-DIAL measurement pairs were inter-compared during the analysed period. The number of MWR-DIAL pairs is larger during spring (Sep-Oct-Nov). This is because the DIAL measurement campaigns become more intense in those months when the $\mathrm{AOH}$ approaches and overpasses southern South America (Wolfram et al., 2012). Between December 2014 and July 2015, there were no DIAL measurements. On the other hand, we observe that the number of MWR-MLS inter-compared pairs during spring and summer amounting to 59 was larger than that during autumn and winter with 25 pairs. February, March and July do not present inter-compared measurements because few MWR observations were retrieved and did not match MLS observations according to the spatial and temporal overlap criteria defined in the methodology section.

\subsubsection{MWR-MLS comparison}

Figure 5a, c, e show the time series of the MLS and MWR ozone mixing ratios for 27,37 and $65 \mathrm{~km}$ for measurements when the opacity was less than 0.29 (see Sect. 2.3). The behaviour of both data series is similar for all altitudes considered. Figure 5b, d, f present the scatterplot between both instruments at different altitudes and the linear regression together with the correlation coefficient $(R)$. Table 1 summarizes the results of the comparisons between datasets.

We compared $N=84$ MWR-MLS measurement pairs, taking into account the spatial selection criteria according to the location of the MLS measurement with respect to the location of the MWR (LatOAPA $\pm 0.2^{\circ}$; LongOAPA $\pm 5^{\circ}$ ).

The linear regression analysis at $27 \mathrm{~km}$ presents a slope of 1.01 and an intercept value of 0.25 . The correlation coefficient $(R)$ of 0.65 reflects considerable correlation for both datasets. The MBE was calculated to analyse the bias between ground-based and satellite data. We obtained a value of $+5 \%$, indicating an MWR overestimation with respect to the MLS.

Unlike the average ozone mixing ratio at $27 \mathrm{~km}$, the MBE at $37 \mathrm{~km}$ reflected an underestimation of the ozone mixing ratio of $-11 \%$ compared with MLS. Fiorucci et al. (2013) also presented differences ranging between $-8 \%$ and $-18 \%$ in the $17-50 \mathrm{~km}$ vertical range, reaching $\sim-18 \%$ at $37 \mathrm{~km}$. The regression analysis presents a slope of 0.96 and an intercept of 0.44. Similarly, the correlation coefficient at this altitude was calculated $(R=0.63)$ to evaluate the correlation between MWR and MLS at this altitude.

The best correspondence was found at $65 \mathrm{~km}$. The linear regression presents a slope near to the unity $(0.95)$ with an intercept close to zero $(-0.02 \mathrm{ppm})$. The correlation between measurements was also close to unity $(R=0.88)$, which reflects very good agreement. Finally, a MBE value of $-7 \%$ shows an underestimation of the average MWR measurements in comparison to MLS.

The difference between measurements can be attributed to the typical uncertainties of each instrument, although another source of difference could be explained by the noncollocated measurements inter-compared. This point is discussed in Sect. 5.

\subsubsection{MWR-DIAL comparison}

Figure 6a shows the ozone mixing ratio measured by the MWR and DIAL for $27 \mathrm{~km}$ at the same time, and a comparison between both instruments by means of a scatterplot (b).

The slope and intercept in the linear regression were 0.93 and $0.36 \mathrm{ppm}(\sim 6 \%$ of the observed average mixing ratio), respectively, with an acceptable correlation coefficient $(R=0.73)$ (Table 1$)$. This reflects a good agreement between both ground-based instruments at $27 \mathrm{~km}$. Unlike the MWR-MLS inter-comparison at $27 \mathrm{~km}(R=0.65)$, MWR and DIAL instruments are installed at the same place, which 

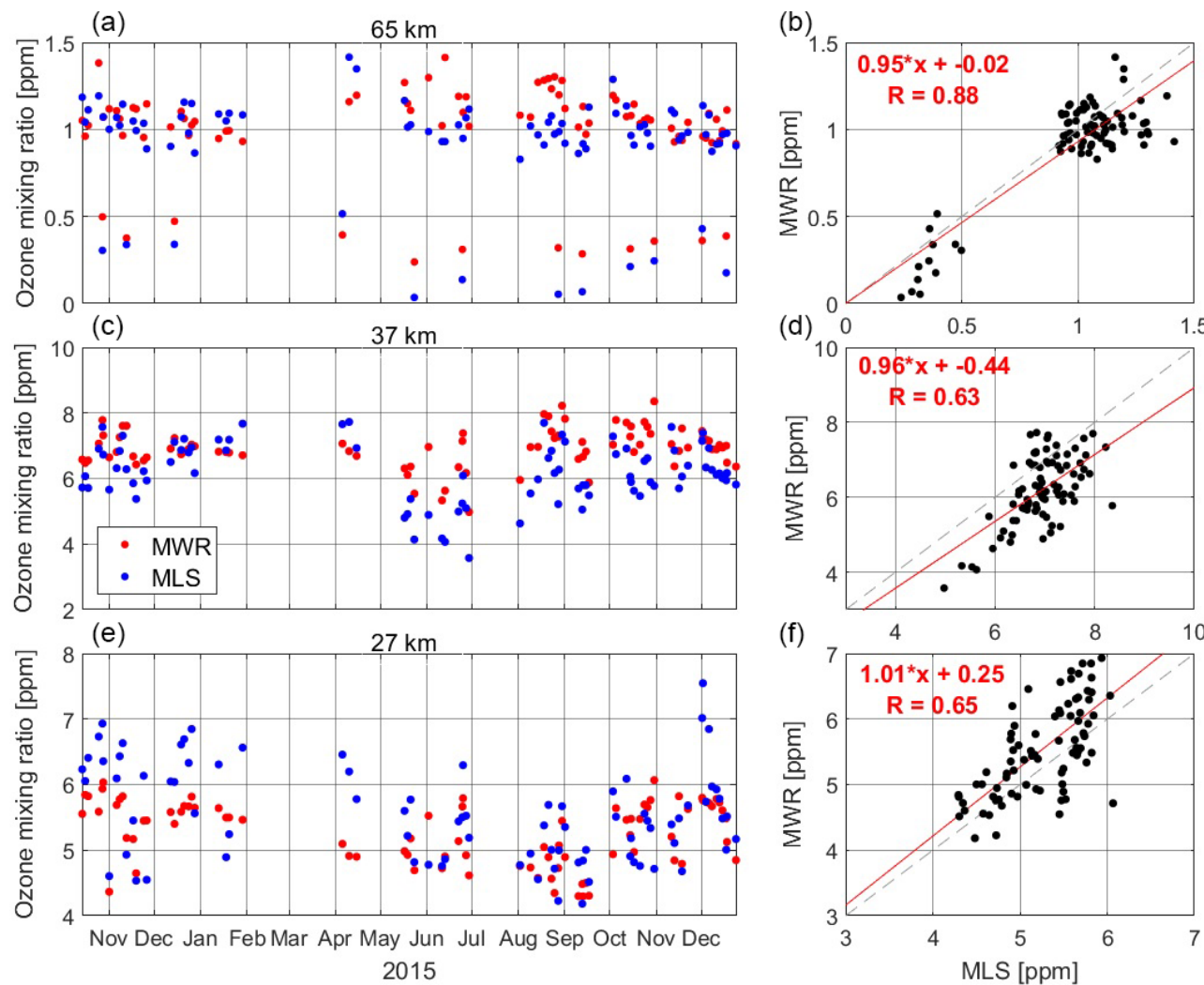

Figure 5. (a, c, e) MLS (red dots) and MWR (blue dots) ozone mixing ratios at the same time and within a box of \pm 0.2 in latitude and $\pm 5^{\circ}$ in longitude from the OAPA location for three altitudes: 27, 37, and $65 \mathrm{~km}$. The analysed period covers from October 2014 to December 2015 , with a total of 84 overlap measurements; $(\mathbf{b}, \mathbf{d}, \mathbf{f})$ scatterplot between MLS and MWR measurements for the three altitudes analysed.

Table 1. Statistical parameters of the MWR with respect to the MLS and DIAL measurement inter-comparison.

\begin{tabular}{rrrrrrr}
\hline & \multicolumn{7}{c}{ Intercept } \\
\cline { 2 - 7 } & Alt. & $N$ & Slope & Intercept $(\mathrm{vmr}(\mathrm{ppm}))$ & $R$ & MBE \\
\hline \multirow{2}{*}{ MWR-MLS } & $27 \mathrm{~km}$ & 84 & 1.01 & 0.24 & 0.65 & $+5 \%$ \\
& $37 \mathrm{~km}$ & 84 & 0.96 & -0.43 & 0.63 & $-11 \%$ \\
\multirow{3}{*}{ MWR-DIAL } & $65 \mathrm{~km}$ & 84 & 0.95 & 0.02 & 0.88 & $-7 \%$ \\
& $27 \mathrm{~km}$ & 30 & 0.93 & 0.36 & 0.73 & $-1 \%$ \\
\hline
\end{tabular}

$N$ : number of inter-comparison pairs; $R$ : correlation coefficient; MBE: mean bias error.

might explain, in part, the better correlation. The observed discrepancy can be attributed to instrumental uncertainties.

\subsection{Short-term ozone variability}

To study the short-term ozone mixing ratio variability related to the AOH influence over Río Gallegos, an extreme event of rapid variation that occurred between 15 and 20 November 2014 was analysed using the MWR measurements at 27 and $37 \mathrm{~km}$. A $3 \mathrm{~h}$ running mean was applied.

Zonal ozone mixing ratio climatologies were calculated from the MLS ozone profile measurements from 2004 to 2016 at both altitudes, interpolated to the latitude of Río
Gallegos to analyse differences between measurements and mean values presented at those latitudes.

Finally, the APV was calculated using the MIMOSA model for these altitudes to interpret the ozone measurements.

\subsubsection{Description of the case study}

After analysing the correspondence of the MWR measurements to independent instruments, here we analyse a shortterm ozone variation for an atypical case study of the influence of the AOH over Río Gallegos during November 2014. 

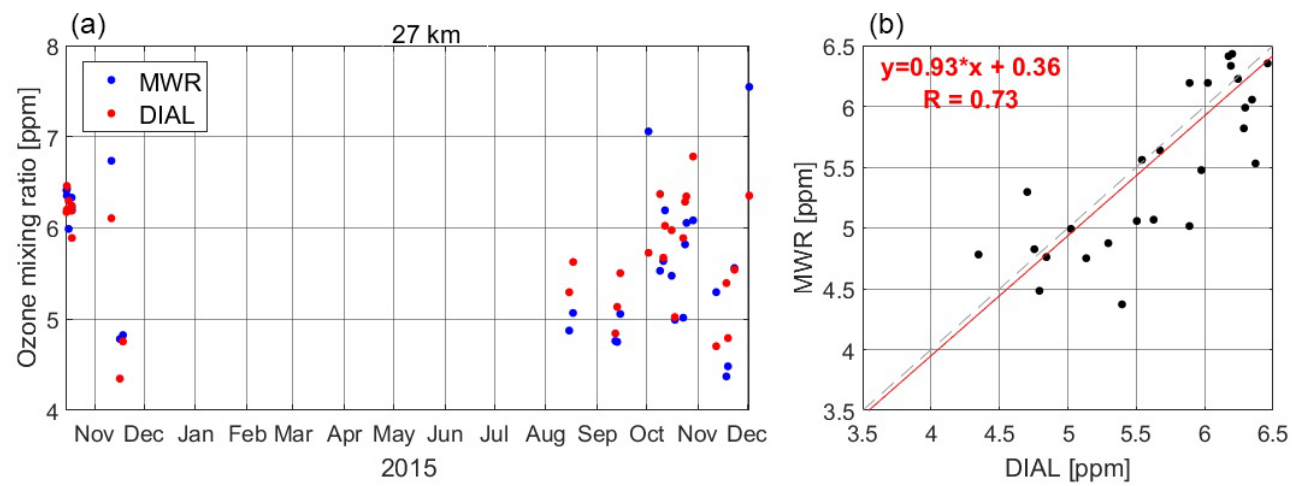

Figure 6. (a) DIAL (red dots) and MWR (blue dots) ozone mixing ratio at the same time for $27 \mathrm{~km}$ between October 2014 and December 2015; (b) scatterplot between DIAL and MWR measurement.
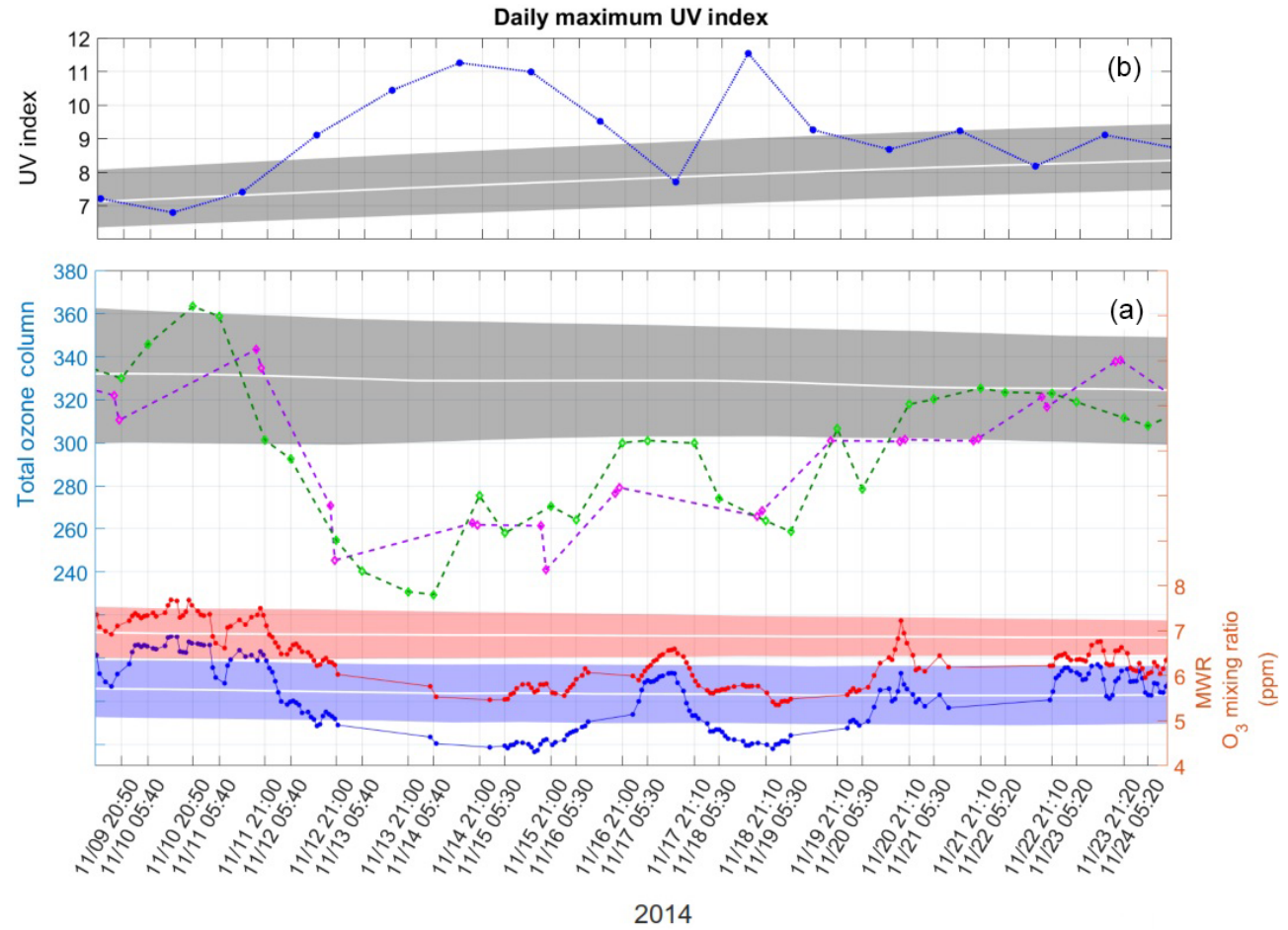

Figure 7. Atypical event of Antarctic ozone hole influence over Río Gallegos. (a) Time evolution of the MWR ozone mixing ratio at 27 km (red line) and $37 \mathrm{~km}$ (blue lines). Light red and light blue areas represent the ozone mixing ratio zonal climatology at both altitudes calculated using the MLS database (2004-2016). (a) Time evolution of the total ozone column measured with the ground-based SAOZ instruments (green dots) and OMI (purple dots) in Dobson units. White line and grey area represent the climatology and 1 SD calculated using the OMI database (2004-2017). (b) Time evolution of the daily maximum Ultraviolet Index measured with the YES UVB-1 ground-based solar radiometer at the OAPA. White line and grey area represent the climatological UVI at noon in Río Gallegos.

Figure 7a shows the time evolution of the MWR ozone mixing ratio at 27 (blue line) and $37 \mathrm{~km}$ (red line) by November 2014 with their respective zonal mean value (white line) and 1 standard deviation (SD) (light blue and light red, respectively). The statistical quantifiers were calculated from the MLS profile dataset, interpolated to the latitude of Río Gallegos from 2004 to 2016. Both altitudes present similar behaviours. We observe a rapid ozone decrease at both altitudes from 11 November at 19:30 local time (LT) to 15 November. The minimum value at $27 \mathrm{~km}$ is reached at 06:30 LT, while at $37 \mathrm{~km}$ it occurs at 05:30 LT, and both minimums are far more than 2 SD from the mean value (around less than $25 \%$ and $20 \%$ with respect to the climatology, respectively). This decrease is related to the influence of the AOH over Río Gallegos, followed by a rapid increase reaching a pick on 17 November at 14:30 at both altitudes. At 
$27 \mathrm{~km}$, the maximum $(\sim 6.1 \mathrm{ppm})$ reaches values above the mean, while at $37 \mathrm{~km}(\sim 6.6 \mathrm{ppm})$ it does not reach the mean. After that, the ozone mixing ratio presents a new local valley reaching the minimum on 19 November at 01:30 LT.

Figure $7 \mathrm{a}$ also shows the time evolution of TOC from the $\mathrm{OMI}$ and the SAOZ installed in the OAPA. The mean value and the SD are depicted by the white line and the shadow area, respectively. We can observe the difference in the frequency of measurements (lower time resolution) with respect to the MWR observations. The general behaviour of both measurements follows the behaviour of the MWR at 27 and $37 \mathrm{~km}$, and it shows the influence of the ozone hole on the TOC with a valley from $\sim 11$ to $\sim 22$ November, where the TOC reached unusual values of $\sim 230$ DU by 14 November ( $\sim 30 \%$ below from climatology), and it is below $1 \mathrm{SD}$ in the whole mentioned period. The OMI measurements did not present the local atypical maximum described above because its time resolution did not allow it to be observed. This atypical event is presented in the SAOZ measurement between 16 November at 21:00 and 17 November at 21:00, although the TOC was below $1 \mathrm{SD}$ from the mean value.

Figure $7 \mathrm{~b}$ (blue dots) presents the time series of the daily maximum Ultraviolet Index (UVI) (near the solar noon) during the low-ozone event described before measurement with a YES UVB-1 radiometer (Yankee Environmental System, Inc.) installed in the OAPA. White line and shadow area are the climatological UVI at noon calculated from the overpass UVI of the OMI satellite between 2004 and 2017 for Río Gallegos. As expected, we observe that the UVI presents an opposite behaviour with respect to the SAOZ and OMI TOC measurements. It is important to note that on 17 November the maximum UVI presents a local minimum value close to the climatology. This local minimum on the maximum UVI could be associated with the short-term ozone recovery observed in the MWR measurement mentioned above (local peak on 17 November).

\subsubsection{Dynamical context. AOH influence}

In order to determine/confirm the polar vortex influence over Río Gallegos and explain the behaviour of the MWR measurement at 27 and $37 \mathrm{~km}$ peaking on 17 November, the APVs from the MIMOSA model were analysed at $675 \mathrm{~K}$ $(\sim 27 \mathrm{~km})$ and $950 \mathrm{~K}(\sim 37 \mathrm{~km})$ for the same period (Figs. 8 and 9). Figure 8 shows the APV for the Southern Hemisphere to describe the state of the polar vortex at both altitudes and the recovery during a short period from 11 to 18 November, while Fig. 9 presents the APV over Río Gallegos at both isentropic levels.

On 11 November, the polar vortex is out of the continent for both isentropic levels. From 13 November to 16 December, we observed low values of APV over Río Gallegos, which is correlated with the decrease in ozone amount for the MWR at 27 and $37 \mathrm{~km}$ (Fig. 7) and with the decrease in the TOC from OMI and SAOZ, due to polar air masses. On
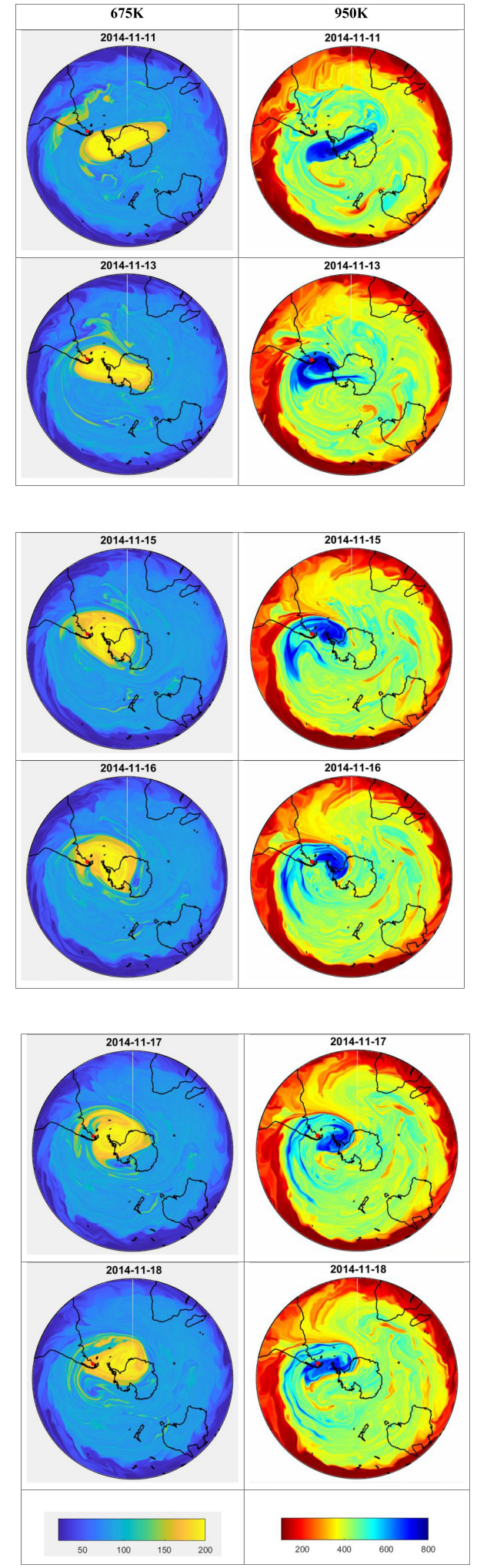

Figure 8. Advected potential vorticity maps assimilated with the MIMOSA model. Maps show the evolution of the polar vortex for two isentropic levels with potential temperatures of $675 \mathrm{~K}$ (left) and $950 \mathrm{~K}$ (right). 

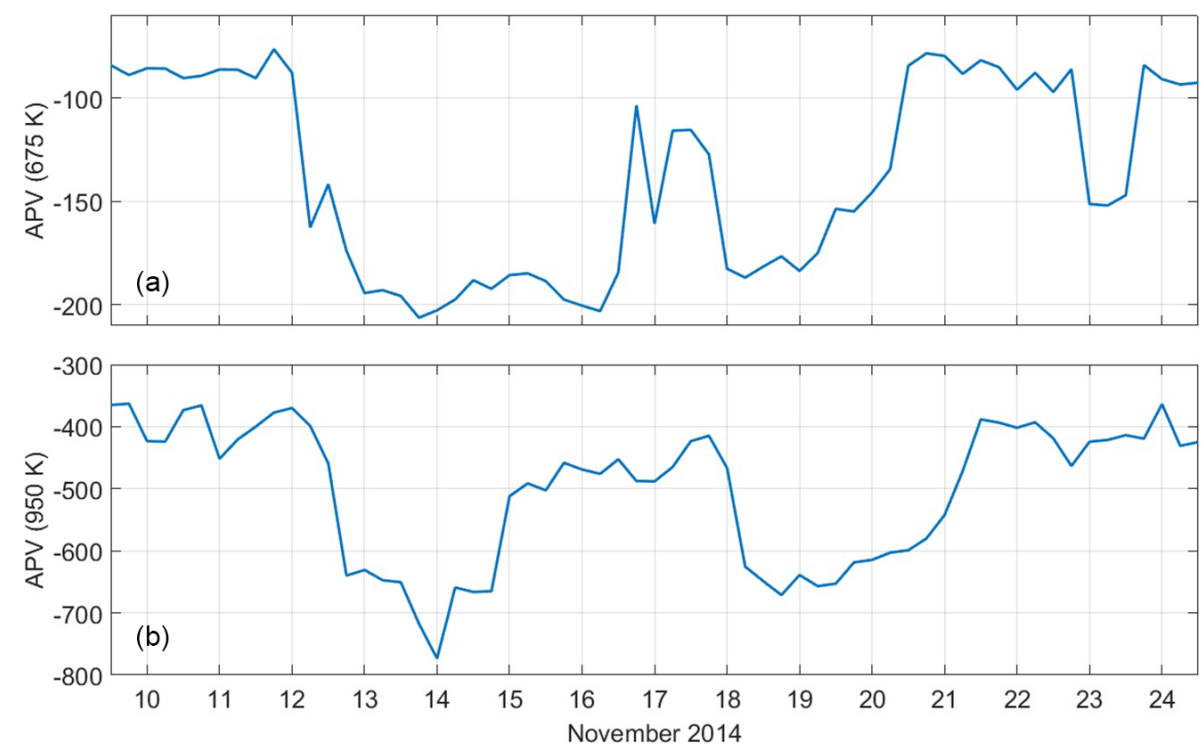

Figure 9. Time evolution of advected potential vorticity assimilated with the MIMOSA model over Río Gallegos (-51.6; -69.3) at 675 K (a) and $950 \mathrm{~K}(\mathbf{b})$.

17 November, the APV map shows the formation of a yellow tongue at $675 \mathrm{~K}$ reflecting the lower values of APV between $\sim-39$ and $\sim-43^{\circ}$ of latitude over the continent. In the APV map at $950 \mathrm{~K}$, some blue filaments with low APV values can be observed at similar latitudes. We observe that Río Gallegos is out of this tongue and these filaments on 17 November, and air masses from outside the polar vortex were passing over Río Gallegos. On 18 November, poor-ozone air masses reach Río Gallegos again, and the increase in ozone mixing ratio at both altitudes is observed in Fig. 7.

The APV over Río Gallegos (Fig. 9) at $675 \mathrm{~K}(\sim 27 \mathrm{~km})$ and $950 \mathrm{~K}(\sim 37 \mathrm{~km})$ presents a similar behaviour of the MWR measurements at 27 and $37 \mathrm{~km}$. At both altitudes, the APV decreased from 12 to 14 November, with an increase around 17 November, followed by a new decrease on 18 November. For $950 \mathrm{~K}$, the increase before 17 November is smoother than at $675 \mathrm{~K}$, which gives an account that the polar vortex at $37 \mathrm{~km}$ reached Río Gallegos earlier than at $27 \mathrm{~km}$.

Both analyses in Figs. 8 and 9 confirm that the polar vortex retreated from Río Gallegos for a short period around 17 November, which explains the local maximum in the ozone mixing ratio detected by the MWR for both altitudes in Fig. 7. Thus, the high time resolution of the MWR measurements enables us to observe the short-term ozone variation and determine the influence of the AOH over Río Gallegos at each altitude, with a time resolution of $1 \mathrm{~h}$, when the atmospheric conditions allow measurements to be taken.

\section{Discussion}

It is well known that the southern part of South America is affected by frequent abrupt intrusions of the $\mathrm{AOH}$ dur- ing the spring (Wolfram et al., 2012; Kirchhoff et al., 1997a; WMO, 2011b, 2012, 2013). As a consequence of this phenomenon, the ozone amount in the middle atmosphere suffers from sudden variations in short time periods of the order of hours. In this paper we presented a case study of shortterm ozone mixing ratio variability at different isentropic levels over Río Gallegos, Argentina, during November 2014, as a consequence of the polar vortex influence over this region. The study could be conducted thanks to the high time resolution of the MWR instrument used. The influence of the polar vortex during the analysed period was confirmed in the APV from the MIMOSA model at two isentropic levels $(675$ and $950 \mathrm{~K})$. We observed filaments of air mass from the polar vortex at both potential temperature levels passing over Río Gallegos. Similar cases of filaments travelling toward mid-latitudes in the Southern Hemisphere have been reported, analysing the APV (Waugh, 1993) without the possibility of reporting the stratospheric ozone amount with the time resolution reported here.

Other satellite or ground-based instruments that monitor the vertical ozone amount, such as MLS or DIAL, have lower time resolution and are not able to observe the short-term ozone variability. This fact shows the capability of the MWR and the need to retrieve the ozone mixing ratio at high time resolution to analyse the short-term variability in these regions directly affected by the passage of the polar vortex at different altitudes.

In addition to the short-term ozone recovery, during the analysed period reductions as a consequence of the ozone hole influence were observed. The ground-based SAOZ and OMI satellite instruments reflected a maximum reduction of around $30 \%$ in TOC. Similar reduction has been found in 
Wolfram et al. (2012) during November 2009, while Kirchhoff et al. (1997a) had reported a maximum reduction of around $60 \%$ by $1992-1994$ at similar latitudes (Punta Arenas, Chile) with respect to the monthly mean values. If we analyse the ozone reduction in altitude, we observed maximum decreases of $20 \%$ and $25 \%$ with respect to the climatology value at 27 and $37 \mathrm{~km}$, respectively. DIAL measurements of ozone profiles carried out in the OAPA have shown maximum differences of around $50 \%$ in SeptemberNovember (WMO, 2011b, 2012, 2013). These results highlight the importance of measurements in sub-polar regions.

The time evolution of the daily maximum UVI was also analysed during the study period. As expected, we find an opposite behaviour with respect to the total ozone column, which is in agreement with other results reported (Casiccia et al., 2008; Wolfram et al., 2012). A local minimum is observed when the measurements of the ozone amount retrieved by the MWR present a maximum at both altitudes.

In Sect. 3.1, we evaluated the correspondence between the MWR with respect to the MLS at 27 and $37 \mathrm{~km}$ and with respect to the ground-based DIAL at $27 \mathrm{~km}$. The MWR-MLS inter-comparison at $27 \mathrm{~km}$ reveals a MBE of $5 \%$, which is consistent with the value obtained by Ohyama et al. (2016). Boyd et al. (2007) also carried out similar inter-comparisons between MLS and two MWRs installed in Mauna Loa, Hawaii, and Lauder, New Zealand. The differences reported for Lauder range from $+7 \%$ to $10 \%$ between $\sim 20$ and $\sim 28 \mathrm{~km}$, while for Mauna Loa differences are around $\sim 3 \%$ (Fig. 1, Boyd et al., 2007). On the other hand, Fiorucci et al. (2013) reported a difference of $10 \%$ at $26 \mathrm{~km}$ of altitude. Thus, the comparisons carried out between MWR and MLS reveal good agreement for the considered altitudes, consistent with the results of other authors.

Similarly, we analysed the MWR-DIAL comparison at $27 \mathrm{~km}$, and we can observe that the correlation coefficient $(R=0.73)$ and the MBE $(1 \%)$ are consistent with those obtained by a similar inter-comparison carried out by other authors. Nagahama et al. (1999) obtained a correlation coefficient of 0.77 and a $\mathrm{MBE}=1 \%$, although that analysis was realized at $38 \mathrm{~km}$. Studer et al. (2013)'s results reflect a $1.43 \%$ difference between MWR and DIAL comparison.

When we compare the MWR with the MLS, it is considered that both instruments are measuring the same air masses, although the location of the satellite measurements differs from the location of the MWR measurements, which can introduce a difference into the ozone mixing ratio measured. These differences could be accentuated during the austral spring, when the AOH occurs, since ozone mixing ratio values can vary considerably over short distances.

At $27 \mathrm{~km}$, we can observe that the correlation between MWR and DIAL $(R=0.73)$ is better than that between MWR and MLS $(R=0.65)$ at the same altitude. In addition, the slope for the linear regression analysis reflects a $1 \%$ relative difference between MWR and DIAL, while MWR presents a positive bias of $5 \%$ with respect to MLS.
One reason why the correspondence between MWR and DIAL is greater with respect to the MLS may be that the two instruments installed on the ground (MWR and DIAL) are monitoring the same air mass, while the distance in the locations of the MLS observations could be introducing differences into the comparison. Figure 3 shows the position of the 84 MLS measurements analysed (yellow crosses) with respect to the location of the OAPA, where the MWR is located. Numbers below crosses indicate the number of each group of MLS measurements in each location. The maximum distance between measurements reaches $\sim 341 \mathrm{~km}$, while the minimum distance is $\sim 23 \mathrm{~km}$ with an average distance of $207 \mathrm{~km}$. Only $22 \%$ of MLS observations are at a distance of less than $100 \mathrm{~km}$ from the MWR, while more than $50 \%$ of the inter-compared observations are farther than $200 \mathrm{~km}$. Therefore, the distance between the considered location of the MLS measurements and the location of the MWR could explain partly the difference between the ozone mixing ratios retrieved from these two instruments. Comparisons between DIAL and MLS were realized by Sugita et al. (2017) for an unusual case of persistence of the AOH over Río Gallegos that occurred during November 2009, and they also attributed part of the differences to the non-co-location of the measurements. Future studies analysing longer datasets will be interesting to determine the influence of the distance between measurements on the ozone mixing ratio differences between instruments in this region.

It is important to note that the MWR and DIAL instruments retrieve ozone in different fundamental units. While the MWR provides the ozone mixing ratio, DIAL provides the ozone number density as a function of altitude. The DIAL unit was converted to the MWR unit for the inter-comparison using the temperature and pressure retrieved from DIAL. Thus, uncertainties in these parameters could be adding uncertainties in the ozone amount in ppm from DIAL.

\section{Conclusions}

We have presented ozone mixing ratio measurements at 27 , 37 and $65 \mathrm{~km}$ with a temporal resolution of $\sim 1 \mathrm{~h}$ from a millimetre-wave radiometer installed at Río Gallegos, Argentina, from October 2014 to December 2015.

The MWR ozone mixing ratio retrieved was compared for the first time with ground-based measurements from the ozone DIAL instrument and satellite measurements from the MLS onboard the AURA in defined overlap altitudes. The comparison revealed good correspondence between independent instruments. The comparison with MLS measurements presents a positive bias of $5 \%$ at $27 \mathrm{~km}$ and a negative bias of $-11 \%$ and $-7 \%$ at 37 and $65 \mathrm{~km}$, respectively. The correlation between measurements at those altitudes was 0.65 , 0.63 and 0.88 at 27,37 and $65 \mathrm{~km}$, respectively. The comparison with the DIAL data at $27 \mathrm{~km}$ reflected a good corre- 
spondence, with a negative bias of $-1 \%$ with a correlation coefficient of 0.73 .

We observed better correspondence between MWR and DIAL at 27 with respect to the MWR-MLS. One reason for this better correspondence may be that the two instruments installed on the ground (MWR and DIAL) are monitoring the same air mass, while the distance in the locations of the MLS observations could be introducing differences into the comparison.

Moreover, this work highlights the capability of the MWR installed in Río Gallegos for the determination of short-term variations of the ozone mixing ratio at different altitudes in this strategic location at the edge of the $\mathrm{AOH}$, making it possible to detect the influence of this phenomenon, as we showed in the atypical study case held in November 2014. The rapid variation of ozone at 27 and $37 \mathrm{~km}$ was analysed in correspondence to the perturbation of the APV derived from the MIMOSA model, which explains the volume mixing ratio peak due to the retreat of the polar vortex for a short time on 17 November. The time evolution of the daily maximum UVI measurements during the analysed period clearly reflects the anti-correlation with the TOC.

The MWR installed in the OAPA covers the lack of ground-based radiometer observations of ozone between Antarctic latitudes and mid-latitudes, allowing us to improve the understanding of the stratospheric and low-mesospheric dynamic using the ozone mixing ratio as a tracer and improving the validation of dynamical models. It is expected to join the MWR to the NDACC Network in future.

Data availability. AURA/MLS satellite data have been downloaded from https://mls.jpl.nasa.gov/ (last access: January 2016), EOS MLS Science Team, MLS/Aura Near-Real-Time L2 Ozone (O3) Mixing Ratio V003, Greenbelt, MD, USA, Goddard Earth Sciences Data and Information Services Center (GES DISC) (Livesey et al., 2011). OMI-ERS2 overpass satellite data are available at https://avdc.gsfc.nasa.gov/index.php?site $=2045907950$, last access: July 2019 (OMI, 2019). APV data assimilated with the MIMOSA model can be solicited directly by email to Nelson Bègue (nelson.begue@univ-reunion.fr). Ozone and UV Index groundbased data (MWR and YES UVB-1) are not available on international networks yet. For these datasets and further information, contact the corresponding author Pablo Facundo Orte by email (porte@citedef.gob.ar).

Author contributions. PFO, EW, AM, NB and HB conceived and designed the analysis. PFO and EW performed the experiment and analysed the data. JLB contributed with the statistical data analysis. AM was the PI of the Saver-Net Project and he was responsible for the MWR instrument. AM and HO contribute with the MWR description. RD was responsible for the YES UVB-1 dataset and contributed with the data analysis. NB performed the MIMOSA model runs together with $\mathrm{HB}$, and they contributed with the PV data interpretation. AP and SGB also assisted with the PV data analysis and with the MIMOSA model information. HO, AM and JS as- sisted with the MWR ozone data inversion. JS and JQ performed the DIAL measurements and ozone profile inversion. PFO wrote the paper. All the authors contributed with the preparation and the improvement of the paper.

Competing interests. The authors declare that they have no conflict of interest.

Acknowledgements. The authors would like to thank JICA and JST for the financial support of the SAVER-Net network and OAPA facilities in the south of Argentina. The French-Argentine ECOS-Sud (A16U01 project) programme is thanked for support research visits between France and Argentina which facilitated the research carried out. JSPS KAKENHI (grant no. JP 18KK0289) is also thanked for supporting the cost of the publication. The authors acknowledge NASA for the availability of the data from AURA/MLS and OMI. The University of Reunion Island is thanked for the access to the MIMOSA model and the CCUR team for the use of the TITAN supercomputer. The authors also want to thank the referees for their valuable comments which helped to improve the manuscript.

Financial support. This research has been supported by JICA and JST, the French-Argentine ECOS-Sud (A16U01 project), and JSPS KAKENHI (grant no. JP 18KK0289).

Review statement. This paper was edited by Petr Pisoft and reviewed by Lucas Vaz Peres and one anonymous referee.

\section{References}

Allen, M., Lunine, J. I., and Yung, Y. L.: The vertical distribution of ozone in the mesosphere and lower thermosphere, J. Geophys. Res., 89, 4841-4872, https://doi.org/10.1029/JD089iD03p04841, 1984.

Asayama, S., Hasegawa, Y., Mizuno, A., Ogawa, H., and Onishi, T.: A Novel Compact Low Loss Waveguide Image Rejection Filter Based on a Backward Coupler with Band Pass Filters for $100 \mathrm{GHz}$ Band, Int. J. Infrared Millim and Terahertz Waves, 36, 445-454, 2015.

Ball, W. T., Alsing, J., Mortlock, D. J., Rozanov, E. V., Tummon, F., and Haigh, J. D.: Reconciling differences in stratospheric ozone composites, Atmos. Chem. Phys., 17, 1226912302, https://doi.org/10.5194/acp-17-12269-2017, 2017.

Ball, W. T., Alsing, J., Mortlock, D. J., Staehelin, J., Haigh, J. D., Peter, T., Tummon, F., Stübi, R., Stenke, A., Anderson, J., Bourassa, A., Davis, S. M., Degenstein, D., Frith, S., Froidevaux, L., Roth, C., Sofieva, V., Wang, R., Wild, J., Yu, P., Ziemke, J. R., and Rozanov, E. V.: Evidence for a continuous decline in lower stratospheric ozone offsetting ozone layer recovery, Atmos. Chem. Phys., 18, 1379-1394, https://doi.org/10.5194/acp18-1379-2018, 2018.

Bencherif, H., Portafaix, T., Baray, J.-L., Morel, B., Baldy, S., Leveau, J., Hauchecorne, A., Keckhut, P., Moorgawa, A., Michaelis, 
M. M., and Diab, R.: LIDAR observations of lower stratospheric aerosols over South Africa linked to large scale transport across the southern subtropical barrier, J. Atmos. Sol.-Terr. Phys., 65, 707-715, 2003.

Bencherif, H., El Amraoui, L., Semane, N., Massart, S., Charyulu, D. V., Hauchecorne, A., and Peuch, V. H.: Examination of the 2002 major warming in the southern hemisphere using groundbased and Odin/SMR assimilated data: stratospheric ozone distributions and tropic/mid-latitude exchange, Can. J. Phys., 85, 1287-1300, 2007.

Bègue, N., Vignelles, D., Berthet, G., Portafaix, T., Payen, G., Jégou, F., Benchérif, H., Jumelet, J., Vernier, J.-P., Lurton, T., Renard, J.-B., Clarisse, L., Duverger, V., Posny, F., Metzger, J.-M., and Godin-Beekmann, S.: Long-range transport of stratospheric aerosols in the Southern Hemisphere following the 2015 Calbuco eruption, Atmos. Chem. Phys., 17, 15019-15036, https://doi.org/10.5194/acp-17-15019-2017, 2017.

Bittencourt, G. D., Bresciani, C., Kirsch Pinheiro, D., Bageston, J. V., Schuch, N. J., Bencherif, H., Leme, N. P., and Vaz Peres, L.: A major event of Antarctic ozone hole influence in southern Brazil in October 2016: an analysis of tropospheric and stratospheric dynamics, Ann. Geophys., 36, 415424, https://doi.org/10.5194/angeo-36-415-2018, 2018.

Boyd, I. S., Parrish, A. D., Froidevaux, L., von Clarmann, T., Kyrölä, E., Russell III, J. M., and Zawodny, J. M.: Ground-based microwave ozone radiometer measurements compared with Aura-MLS v2.2 and other instruments at two Network for Detection of Atmospheric Composition Change sites, J. Geophys. Res., 112, D24S33, https://doi.org/10.1029/2007JD008720, 2007.

Bresciani, C., Bittencourt, G. D., Bageston, J. V., Pinheiro, D. K., Schuch, N. J., Bencherif, H., Leme, N. P., and Peres, L. V.: Report of a large depletion in the ozone layer over southern Brazil and Uruguay by using multi-instrumental data, Ann. Geophys., 36, 405-413, https://doi.org/10.5194/angeo-36-405-2018, 2018.

Brewer, A. W.: Evidence for a world circulation provided by the measurements of helium and water vapor distribution in the stratosphere, Q. J. Roy. Meteor. Soc., 75, 351-363, 1949.

Casiccia, C., Zamorano, F., and Hernandez, A.: Erythemal irradiance at the Magellan's region and Antarctic ozone hole 19992005, Atmosfera, 21, 1-12, 2008.

Chubachi, S.: Preliminary result of ozone observations at Syowa Station from February, 1982 to January, 1983, Mem. Natl. Inst. Polar Res. Jpn. Spec., 34, 13-20, 1984.

Daae, M., Straub, C., Espy, P. J., and Newnham, D. A.: Atmospheric ozone above Troll station, Antarctica observed by a ground based microwave radiometer, Earth Syst. Sci. Data, 6, 105-115, https://doi.org/10.5194/essd-6-105-2014, 2014.

Dobson, G. M. B.: Origin and distribution of polyatomic molecules in the atmosphere, Proc. R. Soc. A,236, 187-193, 1956.

Eriksson, P., Jiménez, C., and Buehler, S. A.: Qpack, a general tool for instrument simulation and retrieval work, J. Quant. Spectrosc. Ra., 91, 47-64, https://doi.org/10.1016/j.jqsrt.2004.05.050, 2005.

Farman, J. C., Gardiner, B. G., and Shanklin, J. D.: Large losses of total ozone in Antarctica reveal seasonal ClOx/NO interaction, Nature, 315, 207-210, https://doi.org/10.1038/315207a0, 1985.

Fiorucci, I., Muscari, G., Froidevaux, L., and Santee, M. L.: Ground-based stratospheric $\mathrm{O} 3$ and $\mathrm{HNO} 3$ measure- ments at Thule, Greenland: an intercomparison with Aura MLS observations, Atmos. Meas. Tech., 6, 2441-2453, https://doi.org/10.5194/amt-6-2441-2013, 2013.

Frith, S. M., Stolarski, R. S., Kramarova, N. A., and McPeters, R. D.: Estimating uncertainties in the SBUV Version 8.6 merged profile ozone data set, Atmos. Chem. Phys., 17, 14695-14707, https://doi.org/10.5194/acp-17-14695-2017, 2017.

Godin, S.: Etude expérimentale par télédétection laser et modélisation de la distribution verticale d'ozone dans la Haute Province, Thèse d'Etat, Paris, 6-69, 1987.

Godin, S., Marchand, M., and Hauchecorne, A.: Influence of the Arctic polar vortex erosion on the lower stratospheric ozone amounts at Haute Provence Observatory $\left(44^{\circ} \mathrm{N}, 6^{\circ} \mathrm{E}\right)$, J. Geophys. Res., 107, 8272, https://doi.org/10.1029/2001JD000516, 2002

Godin-Beekmann, S., Porteneuve, J., and Garnier, A.: Systematic DIAL ozone measurements at Observatoire de Haute-Provence, J. Env. Monitoring, 5, 57-67, 2003.

Harris, N. R. P., Hassler, B., Tummon, F., Bodeker, G. E., Hubert, D., Petropavlovskikh, I., Steinbrecht, W., Anderson, J., Bhartia, P. K., Boone, C. D., Bourassa, A., Davis, S. M., Degenstein, D., Delcloo, A., Frith, S. M., Froidevaux, L., Godin-Beekmann, S., Jones, N., Kurylo, M. J., Kyrölä, E., Laine, M., Leblanc, S. T., Lambert, J.-C., Liley, B., Mahieu, E., Maycock, A., de Mazière, M., Parrish, A., Querel, R., Rosenlof, K. H., Roth, C., Sioris, C., Staehelin, J., Stolarski, R. S., Stübi, R., Tamminen, J., Vigouroux, C., Walker, K. A., Wang, H. J., Wild, J., and Zawodny, J. M.: Past changes in the vertical distribution of ozone - Part 3: Analysis and interpretation of trends, Atmos. Chem. Phys., 15, 9965-9982, https://doi.org/10.5194/acp15-9965-2015, 2015.

Hauchecorne, A., Godin, S., Marchand, M., Heese, B., and Souprayen, C.: Quanti?cation of the transport of chemical constituents from the polar vortex to midlatitudes in the lower stratosphere using the high-resolution advection model MIMOSA and effective diffusivity, J. Geophys. Res., 107, 8289, https://doi.org/10.1029/2001JD000491, 2002.

Heese, B., Godin, S., and Hauchecorne, A.: Forecast and simulation of stratospheric ozone filaments: A validation of a high resolution PV advection model by airborne ozone lidar measurements in winter 1998-1999, J. Geophys. Res., 106, 2001120024, https://doi.org/10.1029/2000JD900818, 2001.

Hendrick, F., Pommereau, J. P., Goutail, F., Evans, R. D., Ionov, D., Pazmino, A., Kyrö, E., Held, G., Eriksen, P., Dorokhov, V., Gil, M., and Van Roozendael, M.: NDACC/SAOZ UV-visible total ozone measurements: improved retrieval and comparison with correlative ground-based and satellite observations, Atmos. Chem. Phys., 11, 5975-5995, https://doi.org/10.5194/acp11-5975-2011, 2011.

Isono, Y., Mizuno, A., Nagahama, T., Miyoshi, Y., Nakamura, T., Kataoka, R., Tsutsumi, M., Ejiri, M. K., Fujiwara, H., Maezawa, H., and Uemura, M.: Ground-based observations of nitric oxide in the mesosphere and lower thermosphere over Antarctica in 2012-2013, J. Geophys. Res.-Space, 119, 7745-7761, https://doi.org/10.1002/2014JA019881, 2014

Jumelet, J., Bekki, S., Seifert, P., Montoux, N., Vernier, J.-P., and Pelon, J.: Microphysical modeling of a midlatitude "polar stratospheric cloud" event: Comparisons against multiwave- 
length ground-based and spaceborne lidar data, J. Geophys. Res., 114, D00H03, https://doi.org/10.1029/2009JD011776, 2009

Kirchhoff, V. W. J. H., Schuch, N. J., Pinheiro, D. K., and Harris, J. M.: Evidence for an ozone hole perturbation at $30^{\circ}$ south, Atmos. Environ., 33, 1481-1488, 1996.

Kirchhoff, V. W. J. H. and Sahai, Y., Casiccia, C. and Zamorano, F., Valderrama, V.: Observations of the 1995 ozone hole over Punta Arenas, Chile, J. Geophys. Res., 102, 16109-16120, 1997a.

Kirchhoff, V. W. J. H., Casiccia, C. and Zamorano, F.: The ozone hole over Punta Arenas, Chile, J. Geophys. Res., 102, 89458953, 1997b.

Kuttippurath, J., Goutail, F., Pommereau, J.-P., Lefevre, F., Roscoe, H. K., Pazmiño, A., Feng, W., Chipperfield, M. P., and Godin Beekmann, S.: Estimation of Antarctic ozone loss from groundbased total column measurements, Atmos. Chem. Phys., 10, 6569-6581, https://doi.org/10.5194/acp-10-6569-2010, 2010.

Levelt, P. F., Hilsenrath, E., Leppelmeier, G. W., Van den Oord, G. H. J., Bhartia, P. K., Tamminen, J., De Haan, J. F., and Veefkind, J. P.: The Ozone Monitoring Instrument, IEEE T. Geosci. Remote Sens., 44, 1093-1101, 2006.

Livesey, N. J., Read, W. G., Froidevaux, L., Lambert, A., Manney, G. L., Pumphrey, H. C., Santee, M. L., Schwartz, M. J., Wang, S., Cofield, R. E., Cuddy, D. T., Fuller, R., Jarnot, R. F., Jiang, J. H., Knosp, B. W., Stek, P. C., Wagner, P. A., and Wu, D. L.: EOS MLS Version 3.3 Level 2 data quality and description document. Technical report, Jet Propulsion Laboratory, 33509, 2011.

London, J.: The observed distribution of atmospheric ozone and its variations, ozone in the free atmosphere, edited by: Whitten, R. C. and Prasad, S. S., New York, Van Nostrand Reinhold, chap. 1, 11-80, 1985.

Marchand, M., Bekki, S., Pazmino, A., Lefèvre, F., GodinBeekmann, S., and Hauchecorne, A.: Model simulations of the impact of the 2002 Antarctic ozone hole on midlatitudes, J. Atmos. Sci., 62, 871-884, 2005.

McDermid, I. S., Bergwer, J. B., Bodeker, G., Boyd, I. S., Brinksma, E. J., Connor, B. J., Farmer, R., Gross, M. R., Kimvilakani, P., Matthews, W. A., McGee, T. J., Ormel, F. T., Parrish, A., Singh, U., Swart, D. P. J., and Tsou, J. J.: OPAL: Network for the Detection of Stratospheric Change ozone profiler assessment at Lauder, New Zealand 1. Blind intercomparison, J. Geophys. Res., 103, 28683-28692, https://doi.org/10.1029/98JD02706, 1998.

McPeters, R. D. and Labow, G. J.: Climatology 2011: An MLS and sonde derived ozone climatology for satellite retrieval algorithms, J. Geophys. Res., 117, D10303, https://doi.org/10.1029/2011JD017006, 2012.

Mizuno, A., Nagahama, T., Morihira, A., Ogawa, H., Mizuno, N., Yonekura, Y., Yamamoto, H., Nakane, H., and Fukui, Y.: Millimeter-wave radiometer for the measurement of stratospheric $\mathrm{ClO}$ using a superconductive (SIS) receiver installed in the southern hemisphere, Int. J. Infrared Millimeter Waves, 23, 981-995, https://doi.org/10.1023/A:1019618917005, 2002.

Nagahama, T., Nakane, H., Fujinuma, Y., Ninomiya, M., Ogawa, H., and Fukui, Y.: Ground-based millimeter-wave observations of ozone in the upper stratosphere and mesosphere over Tsukuba, Earth Planet. Space, 51, 1287-1296, https://doi.org/10.1186/BF03351602, 1999.

Nair, P. J., Froidevaux, L., Kuttippurath, J., Zawodny, J. M., Russell, J. M., Steinbrecht, W., Claude, H., Leblanc, T., van Gijsel, J. A. E., Johnson, B., Swart, D. P. J., Thomas, A., Querel, R., Wang, R., and Anderson, J.: Subtropical and midlatitude ozone trends in the stratosphere: Implications for recovery, J. Geophys. Res.-Atmos., 120, 7247-7257, https://doi.org/10.1002/2014JD022371, 2015.

NASA: The $\mathrm{MLS} \mathrm{O}_{3}$ Product, available at: https://mls.jpl.nasa.gov/, last access: January 2016.

Ogawa, H., Mizuno, A., Hoko, H., Ishikawa, H., and Fukui, I.: A $110 \mathrm{ghz}$ sis receiver for radio astronomy, Int. J. Infrared Millimeter Waves, 11, 717-726, 1990.

Ohyama, H., Nagahama, T., Mizuno, A., Nakane, H., and Ogawa, H.: Observations of stratospheric and mesospheric O3 with a millimeter-wave radiometer at Rikubetsu, Japan, Earth Planet. Space, 68, 34-47, https://doi.org/10.1186/s40623-016-0406-4, 2016.

OMI-ERS2/NASA: AURA Validation Data Center, https://avdc. gsfc.nasa.gov/index.php?site $=2045907950$, last access: July 2019.

Orte, P. F.: Procesamiento de señales de un radiómetro de ondas milimétricas para obtener perfiles de ozono y estudios de la radiación solar UV en superficie, PhD Thesis, UTN-FRBA, http: //ria.utn.edu.ar/handle/123456789/20 (last access: July 2019), 2017.

Orte, P. F., Salvador, J., Wolfram, E., D’Elia, R., Nagahama, T., Kojima, Y., Tanada, R., Kuwahara, T., Morihira, A., Quel, E., and Mizuno, A.: Millimeter wave radiometer installation in Río Gallegos, southern Argentina, Int. Conf. on Applications of Opt. and Photonics, edited by: Costa, M. F. M., Vol. 8001, Proceedings of SPIE, https://doi.org/10.1117/12.894578, 2011.

Palm, M., Hoffmann, C. G., Golchert, S. H. W., and Notholt, J.: The ground-based MW radiometer OZORAM on Spitsbergen - description and status of stratospheric and mesospheric O3-measurements, Atmos. Meas. Tech., 3, 1533-1545, https://doi.org/10.5194/amt-3-1533-2010,2010.

Parrish, A., deZafra, R. L., Solomon, P. M., and Barrett, J. W.: A ground-based technique for millimeter wave spectroscopic observations of stratospheric trace constituents, Radio Sci., 23, 106-118, https://doi.org/10.1029/RS023i002p00106, 1988.

Pazmiño, A., Godin, S., Wolfram, E. A., Lavorato, M., Porteneuve, J., Quel, E., and Megie, G.: Intercomparison of ozone profiles measurements by a differential absorption lidar system and satellite instruments at Buenos Aires, Argentina, Optics and Lasers in Engineering, Vol. 40, ISSN 0143-8166, 55-65, 2003.

Pommereau, J. P. and Goutail, F.: $\mathrm{O}_{3}$ and $\mathrm{NO}_{2}$ ground-based measurements by visible spectrometry during Arctic winter and spring 1988, Geophys. Res. Lett., 15, 891-894, https://doi.org/10.1029/g1015i008p00891, 1998.

Pinheiro, D. K., Peres, L., Crespo, N. M., Schuch, N. J., and Leme, N. P.: Influence of the Antacrtic Ozone Hole over South of Brazil in 2010 and 2011, Annual Activity Report 2011, https://doi.org/10.4322/apa.2014.058, 2011.

Portafaix, T., Morel, B., Bencherif, H., Baldy, S., GodinBeekmann, S., and Hauchecorne, A.: Fine-scale study of a thick stratospheric ozone lamina at the edge of the southern subtropical barrier, J. Geophys. Res., 108, 4196, https://doi.org/10.1029/2002JD002741, 2003.

Randel, W. J., Gille, J. C., Roche, A. E., Kumer, J. B., Mergenthaler, J. L., Waters, J. W., Fishbein, E. F., and Lahoz, W. A.: 
Stratospheric transport from the tropics to middle latitudes by planetary-wave mixing, Nature, 365, 533-535, 1993.

Rigby, M., Prinn, R. G., O’Doherty, S., Montzka, S. A., McCulloch, A., Harth, C. M., Mühle, J., Salameh, P. K., Weiss, R. F., Young, D., Simmonds, P. G., Hall, B. D., Dutton, G. S., Nance, D., Mondeel, D. J., Elkins, J. W., Krummel, P. B., Steele, L. P., and Fraser, P. J.: Re-evaluation of the lifetimes of the major CFCs and $\mathrm{CH} 3 \mathrm{CCl} 3$ using atmospheric trends, Atmos. Chem. Phys., 13, 2691-2702, https://doi.org/10.5194/acp-13-2691-2013, 2013.

Rodgers, C. D.: Inverse methods for atmospheric remote sounding: Theory and practice, in: Series on atmospheric and ocean physics, Vol. 2, World Scientific, Singapore, 2000.

Salby, M. L.: Fund, Atmos. Phys. International geophysics series, Academic Press, 61, 29-54, 1996.

Salvador, J. O.: Estudio del comportamiento de la capa de ozono y la radiación UV en la Patagonia Austral y su proyección hacia la comunidad, Tesis de doctorado, UTN-FRBA, 2011.

Solomon, S., Ivy, D. J., Kinnison, D., Mills, M. J., Neely, R. R., and Schmidt, A.: Emergence of healing in the Antarctic ozone layer, Science, 353, 269-274, https://doi.org/10.1126/science.aae0061, 2016.

Steinbrecht, W., Froidevaux, L., Fuller, R., Wang, R., Anderson, J., Roth, C., Bourassa, A., Degenstein, D., Damadeo, R., Zawodny, J., Frith, S., McPeters, R., Bhartia, P., Wild, J., Long, C., Davis, S., Rosenlof, K., Sofieva, V., Walker, K., Rahpoe, N., Rozanov, A., Weber, M., Laeng, A., von Clarmann, T., Stiller, G., Kramarova, N., Godin-Beekmann, S., Leblanc, T., Querel, R., Swart, D., Boyd, I., Hocke, K., Kämpfer, N., Maillard Barras, E., Moreira, L., Nedoluha, G., Vigouroux, C., Blumenstock, T., Schneider, M., García, O., Jones, N., Mahieu, E., Smale, D., Kotkamp, M., Robinson, J., Petropavlovskikh, I., Harris, N., Hassler, B., Hubert, D., and Tummon, F.: An update on ozone profile trends for the period 2000 to 2016, Atmos. Chem. Phys., 17, 1067510690, https://doi.org/10.5194/acp-17-10675-2017, 2017.

Studer, S., Hocke, K., Pastel, M., Godin-Beekmann, S., and Kämpfer, N.: Intercomparison of stratospheric ozone profiles for the assessment of the upgraded GROMOS radiometer at Bern, Atmos. Meas. Tech. Discuss., 6, 6097-6146, https://doi.org/10.5194/amtd-6-6097-2013, 2013.

Sugita, T., Akiyoshi, H., Wolfram, E., Salvador, J., Ohyama, H., and Mizuno, A.: Comparison of ozone profiles from DIAL, MLS, and chemical transport model simulations over Río Gallegos, Argentina, during the spring Antarctic vortex breakup, 2009, Atmos. Meas. Tech., 10, 4947-4964, https://doi.org/10.5194/amt10-4947-2017, 2017.

Vigouroux, C., Blumenstock, T., Coffey, M., Errera, Q., García, O., Jones, N. B., Hannigan, J. W., Hase, F., Liley, B., Mahieu, E., Mellqvist, J., Notholt, J., Palm, M., Persson, G., Schneider, M., Servais, C., Smale, D., Thölix, L., and De Mazière, M.: Trends of ozone total columns and vertical distribution from FTIR observations at eight NDACC stations around the globe, Atmos. Chem. Phys., 15, 2915-2933, https://doi.org/10.5194/acp15-2915-2015, 2015.

Waters, J. W., Froidevaux, L., Jarnot, R. F., Pickett, H. M., Read, W. G., Siegel, P. H., Cofield, R. E., Flower, D. A., Holden, J. R., Lau, G. K., Livesey, N. J., Manney, G. L., Santee, M. L., Wu, D. L., Cuddy, D. T., Lay, R. R., Loo, M. S., Perun, V. S., Schwartz, M. J., Stek, P. C., Thurstans, R. P., Boyles, M. A., Chandra, K. M., Chavez, M. C., Chen, G. S., Chudasama, B. V., Dodge, R.,
Fuller, R. A., Girard, M. A., Jiang, J. H., Jiang, Y., Knosp, B. W., LaBelle, R. C., Lam, J. C., Lee, K. A., Miller, D., Oswald, J. E., Patel, N. C., Pukala, D. M., Quintero, O., Scaff, D. M., Van Snyder, W., Tope, M. C., Wagner, P. A., and Walch, M. J.: The Earth observing system microwave limb sounder (EOS MLS) on the Aura satellite, IEEE Trans. Geosci. Remote Sens., 44, 10751092, 2006.

Waugh, D. W.: Subtropical stratospheric mixing linked to disturbances in the polar vortices, Nature, 365, 535-537, 1993.

Weber, M., Coldewey-Egbers, M., Fioletov, V. E., Frith, S. M., Wild, J. D., Burrows, J. P., Long, C. S., and Loyola, D.: Total ozone trends from 1979 to 2016 derived from five merged observational datasets - the emergence into ozone recovery, Atmos. Chem. Phys., 18, 2097-2117, https://doi.org/10.5194/acp18-2097-2018, 2018.

Wolfram, A. E., Salvador, J., D’Elia, R., Casiccia, C., Leme, N. P., Pazmiño, A., Porteneuve, J., Godin-Beekman, S., Nakane, H., and Quel, E. J.: New Differential absortion lidar for stratospheric ozone monitoring in Patagonia, south Argentina, J. Opt. A, 10, 589-595, 2008.

Wolfram, E., Salvador, J., Pallotta, J., D’Elia, R., Pazmiño, A., Godin-Beeckmann, S., and Quel, E.: Monitoreo de Perfiles de Ozono Estratosféricos con Técnica DIAL en Río Gallegos, anales AFA, 18, ISSN 1850-1168, 2006.

Wolfram, E. A.: Mediciones atmosféricas de ozono y vapor de agua con técnica LIDAR y radiometría solar ultravioleta, tesis de doctorado UNLP, 137-152, 2006.

Wolfram, E. A., Salvador, J., Orte, F., D’Elia, R., Godin-Beekmann, S., Kuttippurath, J., Pazmiño, A., Goutail, F., Casiccia, C., Zamorano, F., Paes Leme, N., and Quel, E. J.: The unusual persistence of an ozone hole over a southern mid-latitude station during the Antarctic spring 2009: a multi-instrument study, Ann. Geophys., 30, 1435-1449, https://doi.org/10.5194/angeo30-1435-2012, 2012.

World Meteorological Organization (WMO): Scientific Assessment of Ozone Depletion: 2010, Global Ozone Research and Monitoring Project-Report No. 52, Geneva, Switzerland, 2011a.

World Meteorological Organization (WMO): Antarctic Ozone Bulletin no. 6-2011, available at: https://www.wmo.int/pages/prog/ arep/documents/ant-bulletin-6-2011.pdf (last access: July 2019), $2011 b$.

World Meteorological Organization (WMO): Scientific Assessment of Ozone Depletion: 2014 Global Ozone Research and Monitoring Project Report, World Meteorological Organization, Geneva, Switzerland, p. 416, 2014.

World Meteorological Organization (WMO): Antarctic Ozone Bulletin no. 4 - 2013, available at: https://www.wmo.int/pages/prog/ arep/documents/ant-bulletin-4-2013.pdf (last access: July 2019), 2013.

World Meteorological Organization (WMO): Antarctic Ozone Bulletin no. 6 - 2012, available at: https://www.wmo.int/pages/prog/ arep/documents/ant-bulletin-6-2012.pdf (last access: July 2019), 2012. 